\title{
Thermal Therapy, Part IV: Electromagnetic and Thermal Dosimetry
}

\author{
Riadh W. Y. Habash, ${ }^{1,2}$ Rajeev Bansal, ${ }^{3}$ Daniel Krewski, ${ }^{1}$ \\ Hafid T. Alhafid ${ }^{1,4}$
}

${ }^{1}$ McLaughlin Centre for Population Health Risk Assessment, Institute of Population Health, University of Ottawa, Ottawa, Ontario, Canada; ${ }^{2}$ School of Information Technology and Engineering, University of Ottawa, Ottawa, Ontario, Canada; ${ }^{3}$ Department of Electrical and Computer Engineering, University of Connecticut, Connecticut, USA; ${ }^{4}$ College of Engineering and Applied Sciences, AI Ghurair University, Dubai, UAE.

Address all correspondence to Riadh W. Y. Habash, McLaughlin Centre for Population Health Risk Assessment, Institute of Population Health, University of Ottawa, 1 Stewart Street, Room 320, Ottawa, Ontario, Canada K1N 6N5; rhabash@site.uottawa.ca.

\begin{abstract}
In this article some of the important techniques in electromagnetic (EM) and thermal dosimetry are reviewed. Three major areas are discussed: modeling power deposition and estimation of EM energy absorbed by tissues exposed to EM radiation, electrical-thermal modeling for thermal therapy with various models of heat transfer in living tissues, and thermal dosimetry using invasive and noninvasive thermometry. Knowledge about the temperature distributions achieved can only be obtained by treatment planning of patient therapy. This process is called thermal therapy planning system (TTPS), which is a large and complex system for design, control, documentation, and evaluation of the treatment that also provides data for treatment optimization. Various imaging techniques for guidance and monitoring necessary for clinical treatments are also discussed. The review concludes by suggesting future avenues for investigations.
\end{abstract}

KEYWORDS: EM interaction, specific absorption rate, bioheat equation, thermal therapy planning system, invasive thermometry, noninvasive thermometry, imaging techniques

\section{INTRODUCTION}

Dosimetry refers to the accurate measurement of doses. Electromagnetic (EM) dosimetry, that is, the measurement or calculation of the EM radiation absorbed by humans in radiation fields, has become important as the use of EM devices in our society has increased. Additionally, dosimetry requires the measurement or determination by calculation of induced current density, specific absorption (SA), or specific absorption rate (SAR), as well as distributions in objects including models (phantoms), animals, humans, or even human body parts exposed to 
EM fields. ${ }^{1,2}$ At lower frequencies of EM radiation (below approximately $100 \mathrm{kHz}$ ), many biological effects are quantified in terms of the current density in tissue and this parameter is most often used as a dosimetric quantity. At higher frequencies of radiation, many (but not all) interactions are due to the rate of energy deposition per unit mass. Thus, at high frequencies, SAR is used as the dosimetric measure. ${ }^{3}$

Dosimetry, either theoretical or experimental, is based on modeling of the human body, which presents obvious differences between individuals. The variations are related to the size and shape of the body, to the distribution of biological tissues, and to the dielectric characteristics of each tissue. ${ }^{4}$

The accuracy of thermal therapy treatment simulation determines its role in prospective treatment planning and dosimetry for the individual patient. Today, a major limitation of thermal therapies is the lack of detailed information available to guide the therapy. ${ }^{5-7}$ Inadequate thermal doses to tumors can cause failure of treatments. In order to compare different treatments and to correlate the treatment data with the clinical results, it is mandatory to know what temperatures are reached in the target volume. ${ }^{8}$

In thermal therapy, the temperature at the treatment location must be controlled and depends on the type of therapy technique. Accordingly, accurate thermometry technology is an important requirement. ${ }^{3}$ Highquality thermometry is needed to ensure safe delivery of adequate therapy and provide the quantitative information needed to develop prognostic parameters that will aid research in planning and dosimetry. Temperature measurement methods in the intraorganism are generally classified as invasive or noninvasive. Temperatures are routinely measured invasively, but only sparse measurements can be made. The limited number of measurements may be insufficient for satisfactory temperature distributions in order to assess thermal dosimetry properly. ${ }^{6,9}$ This information in real time would considerably improve the ability to deliver consistently effective temperature distributions. ${ }^{10-}$ ${ }^{13}$ As an efficient thermometry method in thermal therapy, noninvasive methods for temperature measurement without inserting the sensor into the human body are desirable. However, technologies for measuring temperature accurately by noninvasive methods have not been well established. ${ }^{3}$

It is also important to note that imaging is essential for successful treatment. Tumors that are not seen cannot be targeted and residual foci of untreated tumors will continue to grow. Improved imaging techniques should result in improved detection of lesions and more 
accurate determination of tumor margins. Additionally, this should allow improved post-procedural imaging follow-up, which is critical to detect focal areas of untreated or recurrent tumor at early stage when such lesions can be successfully treated. The failure to detect these small focal areas of residual and/or recurrent tumor at an early stage may result in peripheral regrowth, often with unfavorable geometry for successful treatment. ${ }^{14}$

In the literature, important techniques and areas of research in EM dosimetry, ${ }^{15-18}$ thermal dosimetry, ${ }^{19-26}$ treatment planning, ${ }^{27}$ and imaging techniques ${ }^{28-36}$ have been reviewed. Books discussing thermometry and imaging techniques are also available. , $^{3,37-41}$

The purpose of this review is to outline and discuss techniques that have been developed to ensure adequate EM and thermal dosimetry required for thermal therapy. Various models of heat transfer in living tissues with emphasis on Pennes equation have been discussed. Because of limited thermometry, knowledge about the temperature distributions achieved can only be obtained by treatment planning of patient therapy. Various imaging techniques for the guidance and monitoring necessary for clinical treatments are also discussed.

\section{EM INTERACTION WITH BIOLOGICAL MATERIALS}

Interaction of EM energy with a biological material can be studied at two distinct levels:

1. Macroscopic level: for examples, objects, the whole body,

2. Microscopic level: for examples, cells, membranes, and molecules.

Interaction phenomena at both levels, however, cannot be regarded independently. One has to take into account the energy distribution that occurs within an object when placed under EM field. At the macroscopic level of interaction one must consider energy penetration and dissipation phenomena. The microscopic level involves interaction mechanisms at smaller scales. ${ }^{42}$

The effect of interaction of EM waves with biological tissues can be considered as the result of three phenomena: ${ }^{3}$

1. The penetration of EM waves into the living system and their propagation into it,

2. The primary interaction of the waves with biological tissues,

3. The possible secondary effects induced by the primary interaction. 


\section{II.A. Wave Propagation in Tissues}

It is difficult to characterize entirely the propagation of EM fields in the human body given the complexity and nonhomogeneous character of biological tissues. ${ }^{1,2}$ However, computers permit highly accurate evaluations of dosimetry for the human body or part of the body. An EM wave involves both a varying electric field and a varying magnetic field. The propagation of electric and magnetic field is described by the differential form of the Maxwell's equations:

$$
\begin{gathered}
\nabla \times \mathbf{H}=\mathbf{J}+\frac{\partial \mathbf{D}}{\partial t} \\
\nabla \times \mathbf{E}=-\frac{\partial \mathbf{B}}{\partial t} \\
\nabla . \mathbf{B}=0 \\
\nabla . \mathbf{D}=\rho
\end{gathered}
$$

Using the constitutive relationships

$$
\begin{aligned}
& \mathbf{B}=\mu \mathbf{H} \\
& \mathbf{D}=\varepsilon \mathbf{E} \\
& \mathbf{J}=\sigma \mathbf{E}
\end{aligned}
$$

where $\mathbf{E}$ is the electric field in volts per meter $(\mathrm{V} / \mathrm{m}), \mathbf{H}$ is the magnetic field in amperes per meter $(\mathrm{A} / \mathrm{m})$, $\mathbf{J}$ is the current density in amperes per square meter $\left(\mathrm{A} / \mathrm{m}^{2}\right), \mathbf{B}$ is the magnetic flux density in webers per square meter $\left(\mathrm{Wb} / \mathrm{m}^{2}\right), \mathbf{D}$ is the electric displacement in coulombs per square meter $\left(\mathrm{C} / \mathrm{m}^{2}\right), \mu$ is the permeability in henries per meter $(\mathrm{H} / \mathrm{m})$, $\varepsilon$ is the permittivity in farads per meter $(\mathrm{F} / \mathrm{m})$, and $\sigma$ is the conductivity in $\Omega^{-1} \mathrm{~m}^{-1}$.

Generally, three different quantities describe the permittivity of the medium: $\varepsilon, \varepsilon_{0}$, and a dimensionless quantity known as the relative permittivity $\varepsilon_{r}$ or the dielectric constant, which is defined as the permittivity relative to that of free space $\left(\varepsilon_{0}=8.854 \times 10^{-12} \mathrm{~F} / \mathrm{m}\right)$. The three quantities are related by

$$
\varepsilon=\varepsilon_{0} \varepsilon_{r}
$$

The dielectric constant of free space is $\varepsilon_{r}=1$. This value is assumed for air in most applications. Values of the dielectric constant for most 
biological materials range from 1 to about 80 (in the radio frequency $[\mathrm{RF}] /$ microwave range).

The term permeability refers to the magnetic property of any material. It is a measure of the flux density produced by a magnetizing current. The basic unit of permeability is henries/meter $(\mathrm{H} / \mathrm{m})$. Three different quantities describe the permeability of the medium: $\mu, \mu_{o}$, and a dimensionless quantity known as the relative permeability $\mu_{r}$, which is defined as the permeability relative to that of free space $\left(\mu_{0}=4 \Pi \times\right.$ $\left.10^{-3} \mathrm{H} / \mathrm{m}\right)$. The three quantities are related by

$$
\mu=\mu_{o} \mu_{r}
$$

In the special case of thermal therapy problems, $\mu$ is constant, $\frac{\partial}{\partial t}$ is the equivalent of $j \omega$ where $\omega$ is the angular frequency $(\mathrm{rad} / \mathrm{s})$ at which the power is excited, $\rho$ is zero, and $j$ is $\sqrt{ }-1$.

For isotropic, linear, and nonmagnetic media, Maxwell's equations in the steady-sate form can be written in terms of Faraday's law:

$$
\nabla \times \mathbf{E}=-j \omega \mathbf{B} \text { (Faraday's law) }
$$

and Ampere's law with displacement current:

$$
\nabla \mathbf{x} \frac{\mathbf{B}}{\mu}=\mathbf{J}+j \omega \varepsilon \mathbf{E} \quad \text { (Ampere's law) }
$$

Equations (5) and (6) allow the electric and magnetic fields present in the biological system to be predicted. It is quite common to assume the constitutive parameters to be independent of the temperature, allowing the electric field to be predicted without knowledge of the temperature field. In ablation therapies, where temperature may exceed $100^{\circ} \mathrm{C}$, this assumption is no longer valid and the thermal and EM prediction problems become coupled. ${ }^{43}$

To obtain the simplest solution for the electric and magnetic fields, we first consider wave propagation in free space, that is, with no electric charges $(\rho=0)$ and no current $(\mathbf{J}=0)$. The solution is (arbitrarily) restricted to only one electric field component $E_{x}$ spatially varying with $z$ only. By combining the set of four relations in Equation (1), a simplified form of the wave equation is obtained:

$$
\frac{\partial^{2} E_{x}}{\partial z^{2}}+\frac{k^{2}}{\omega^{2}} \frac{\partial^{2} E_{x}}{\partial t^{2}}=0
$$


where the phase constant $k=\omega\left(\mu_{0} \varepsilon_{0}\right)^{1 / 2}=2 \pi / \lambda_{0}\left(\lambda_{0}=\right.$ wavelength in free space and $\omega=$ angular frequency). Solutions of this second-order differential equation correspond to plane traveling waves of the form:

$$
\mathbf{E}_{x}(z, t)=\mathbf{E}_{x} e^{j(\omega t-k z)}
$$

Where $E_{x}$ is the magnitude of the wave in the $x$ direction and $t$ is the time. For propagation in a homogeneous dielectric medium, the plane wave expressions for $E$ and $H$ will include a complex propagation constant replacing a real phase constant:

$$
k^{*}=j \omega\left[\mu_{0} \varepsilon_{0}\left(\varepsilon^{\prime}-\varepsilon^{\prime \prime}\right)\right]^{1 / 2}=\alpha+\mathrm{j} \beta
$$

Where $\alpha$ is the attenuation constant and $B$ is the phase constant for a uniform plane wave.

Expressions for $\alpha$ and $B$ are:

$$
\begin{gathered}
\alpha=\frac{2 \pi}{\lambda_{o}}\left(\frac{\varepsilon^{\prime}}{2}\right)^{1 / 2}\left\{\left[1+\left(\frac{\varepsilon^{\prime \prime}}{\varepsilon^{\prime}}\right)^{2}\right]^{1 / 2}-1\right\}^{1 / 2} \text { nepers/m } \\
\beta=\frac{2 \pi}{\lambda_{o}}\left(\frac{\varepsilon^{\prime}}{2}\right)^{1 / 2}\left\{\left[1+\left(\frac{\varepsilon^{\prime \prime}}{\varepsilon^{\prime}}\right)^{2}\right]^{1 / 2}+1\right\}^{1 / 2} \mathrm{rad} / \mathrm{m}
\end{gathered}
$$

where $\frac{\varepsilon^{\prime \prime}}{\varepsilon^{\prime}}$ is the loss tangent. The value of a determines the depth of penetration $\delta$ in tissues, which is the depth by which the electric field amplitude is reduced by $e^{-1}$ of its original amplitude and can be calculated as:

$$
\delta=\frac{1}{\alpha}
$$

Depth of penetration is important for radiative methods of heating.

\section{II.B. Modeling Power Deposition}

Living systems have a large capacity for compensating for the effects induced by external influences, in particular EM sources. This is very often overlooked, and thus is one more reason that conclusions 
derived from models have to be taken with precaution. Physiological compensation means that the strain imposed by external factors is fully compensated and the organism is able to perform normally. Pathological compensation means that the imposed strain leads to the appearance of disturbances within the functions of the organism and even structural alterations may result. The borderline between these two types of compensation is not always easy to determine. ${ }^{3}$

To obtain the solution for the equations of EM deposition inside biological systems, it is necessary to choose a calculation method. Sometimes the geometry of the model is simple enough (one-dimensional models) that these equations can be solved by analytical methods. However, most models have a complex geometry (especially those based on a very realistic anatomy), with regions of different characteristics, and a numerical method has to be employed. Analytical techniques may be used to predict EM fields deposited inside modeled tissues by solving Maxwell's equations for general source configurations of canonical homogenous bodies. For inhomogeneous bodies, one must resort to numerical analysis. Several early analytical studies have been carried out employing the plane wave transmission-line model approach to evaluate the EM fields and to determine the energy deposited in a lossy, semi-infinite, and homogenous target (man and animals) at high frequency EM radiation. ${ }^{44,45}$ Other models have also been employed, such as spheres, ${ }^{46}$ prolate spheroidal, ${ }^{1,47,48}$ ellipsoids, ${ }^{49,50}$ and multilayer elliptic cylinder. ${ }^{51,52}$ Values of field, absorbed energy in the human body, and the effect of layering on energy deposition have been also obtained. ${ }^{53-56}$

The use of numerical modeling techniques has improved the understanding of power deposition in human bodies with EM energy. Several numerical techniques have been investigated over the past several years. The finite-difference time-domain (FDTD) method is extremely versatile for bioelectromagnetic problems. The FDTD has been used for modeling whole-body or partial-body EM exposures. The human body is modeled as a nonmagnetic, isotropic, linear EM material at the frequencies of interest. The time-dependent Maxwell's equations (Equation 1) are implemented for a lattice of subvolumes or Yee space cells that may be cubical or parallelepiped with different dimensions $\Delta x, \Delta y$, and $\Delta z$ in the $x, y$, and $z$ directions, respectively. The components of $\mathrm{E}$ and $\mathrm{H}$ are positioned about each of the cells at half-cell intervals and calculated alternately with half-time steps, $\Delta t / 2$. This procedure has been well documented in the literature and its implementation for bioelectromagnetic problems is available in several publications. ${ }^{57-73}$ 
Another numerical technique that is usually applied to bioelectromagnetic problems is the finite element method (FEM). This method requires the complete volume of the configuration to be meshed as opposed to surface integral techniques, which only require surfaces to be meshed. Each mesh element can have different material properties from those of neighboring elements. The aim of the FEM analysis is to determine the field quantities at the nodes (corners of the elements). The drawback of this method is that, for complicated bodies, it is difficult and sometimes impossible to carry out the integration procedure over the entire body. The details of the FEM and its implementation for bioelectromagnetic problems are available. ${ }^{74-86}$

\section{II.C. Specific Absorption Rate (SAR) Modeling}

When considering EM interaction with biological systems, it is important to distinguish between levels of fields outside the body (the exposure) and field levels or absorbed energy within body tissues (the dose). The exposure is measured in terms of the electric (E) or magnetic $(\mathrm{H})$ field strength, or power density incident on the body. The dose depends on the exposure, as well as on body geometry, size, its orientation with respect to the field, and other factors. ${ }^{87}$ The central issue concerning the dosimetric assessment of the absorption of EM energy by biological tissues is how much is absorbed and where it is deposited. ${ }^{88}$ This is usually quantified in terms of the SAR, which is the mass-normalized rate at which EM energy is absorbed by the object at a specific location and thus is a good predictor of thermal effects. In the context of RF or microwaves, two alternatives are used, allowing the SAR evaluation from either electric field or temperature measurement. Accordingly, SAR is defined as:

$$
\mathrm{SAR}=\frac{\sigma|\mathrm{E}|^{2}}{\rho}=c \frac{d T}{d t}
$$

where, $\sigma$ is the electrical conductivity in siemens per meter $(\mathrm{S} / \mathrm{m}), \rho$ is the mass density in kilogram per cubic meter $\left(\mathrm{kg} / \mathrm{m}^{3}\right), c$ is the specific heat in joules per kilogram per temperature in degrees Kelvin (J/kg K) and $\frac{d T}{d t}$ is the time derivative of the temperature in degrees Kelvin per second $(\mathrm{K} / \mathrm{s})$. The unit of SAR is watts per kilogram $(\mathrm{W} / \mathrm{kg})$.

It is clear from Equation (11) that the localized SAR is directly related to the internal electric field. Calculation of the internal field is, however, difficult to achieve because it is strongly dependent on many factors. These include the nature (near- or far-field zone) and frequency 
of the incident field, the shape and dimension of the object, the dielectric properties of the object, and whether or not the object is insulated from earth. ${ }^{88}$ Specific absorption rate is a useful dosimetric measurement between approximately $100 \mathrm{kHz}$ and $10 \mathrm{GHz}$. At frequencies below about $100 \mathrm{kHz}$, a more useful measure of dose is often the electric field strength in tissue, in units of volts per meter.

There are two major types of SAR: a whole-body average, and a local (spatial) peak when the power absorption takes place in a confined body region, as in the case of a head exposed to a mobile phone. Whole body SAR measurements are useful for estimating elevations of the core body temperature. As SAR increases, the possibility for heating and, therefore, tissue damage also rises. The whole-body SAR for a given organism will be highest within a certain resonant frequency range, which is dependent on the size of the organism and its orientation relative to the electric and magnetic field vectors and the direction of wave propagation. For an average human, the peak whole-body SAR occurs in a frequency range of $60-80 \mathrm{MHz}$, while the resonant frequency for a laboratory rat is about $600 \mathrm{MHz}{ }^{89}$

Both types of SAR are averaged over a specific period of time and tissue masses of 1 or $10 \mathrm{~g}$ (defined as a tissue volume in the shape of a cube). Averaging the absorption over a larger amount of body tissue gives a less reliable result. The 1-g SAR is a more precise representation of localized $\mathrm{RF}$ energy absorption and a better measure of SAR distribution. Local SAR is generally based on estimates from the whole-body average SAR. It incorporates substantial safety factors (on the order of 10 or 20)..$^{90,91}$

Deposition of energy, usually stated in terms of SAR, although useful for quality control and intercomparison of equipment, is not necessarily related to tissue temperature and, therefore, also not related to cytotoxicity.

\section{II.D. Thermal Dose}

A serious problem in thermal therapy is the definition of clinically meaningful dose. Thermal dose may be defined as the length of exposure of a particular body part to a particular temperature. The actual temperature/heat-dose distribution in the tissue is one of the most important factors that determine the effectiveness of treatment. ${ }^{92}$ Usually, temperature distribution during thermal therapy is inhomogeneous. The major cause of the temperature inhomogeneity is that during treatment the systemic temperature remains low. This 
implies that incoming arterial blood is at the body core temperature and thus that discrete vasculature in combination with a heterogeneous blood perfusion field causes large thermal underdosage in the heated volume. ${ }^{93}$

Two key papers, published in the mid-1980s, attracted attention to the opportunity to assess efficacy of cell killing with heat. ${ }^{94,95}$ These papers established the first concepts for thermal dosimetry and indicated that significant cell killing could occur if cells or tissues were heated to more than $42^{\circ} \mathrm{C}$ for 1 hour or more. The effect of nonuniform temperature distributions on cytotoxicity is amplified by the temperature threshold effect, which may vary from tumor to tumor and from normal tissue to tissue.

The thermal dose is typically presented in equivalent minutes to $43^{\circ} \mathrm{C}$. It is assumed that $43^{\circ} \mathrm{C}$ represents the so-called "break" point in the Arrhenius plot. ${ }^{96,97}$ Every increase of temperature by ${ }^{\circ} \mathrm{C}$ above $43^{\circ} \mathrm{C}$ doubles the time in minutes equivalent to $43^{\circ} \mathrm{C}$. Conversely, every decrease of temperature by $1^{\circ} \mathrm{C}$ below $43^{\circ} \mathrm{C}$ results in a reduction of equivalent time by a factor of $\sim 4$ (range from 2-6). These rules are consistent with laboratory data, proven for a variety of cell lines with a wide range of temperature sensitivities. ${ }^{26}$

Thermal dosimetry is complicated by temperature heterogeneity within tumors, biological variations, and development of thermotolerance. This heterogeneity results from heterogeneous energy deposition and also from perfusion-related conductive cooling. ${ }^{95,98-100}$ Moreover, the temperature heterogeneity is temporally dynamic ${ }^{101}$ and heat effects are time dependent. ${ }^{102}$ These issues have made development of thermal dosimetry challenging.

Thermal dose formulations that have taken into account both the temperature distribution and time at various temperatures have shown good correlations with complete response rates ${ }^{94,103}$ and duration of local tumor control. ${ }^{104,105}$

\section{II.E. Thermal Measurements}

It is particularly important to be able to make accurate thermal measurements in human beings. While a comprehensive database of thermal effects is available, it mainly concerns animal studies and in vitro studies. Several methods of biological analysis, listed below, are based on thermal measurements.

1. Calorimetric methods are particularly suited for in vitro 
measurements, in which heating and cooling data can be analyzed to estimate the energy absorbed by an exposed sample.

2. Thermometric methods are used to measure the temperature due to microwaves with particular types of nonperturbing thermometers. There are only a few commercially available.

3. Thermographic techniques are used to measure temperature with particular thermographic cameras.

The rate of temperature change in the subcutaneous tissue in vitro exposed to EM radiation is related to SAR as:

$$
\frac{\Delta T}{\Delta t}=\frac{\left(\mathrm{SAR}+P_{m}-P_{c}-P_{b}\right)}{c}
$$

where $\Delta T$ is the temperature increase, $\Delta t$ is the exposure duration, $P_{m}$ is the metabolic heating rate, $P_{c}$ is the rate of heat loss per unit volume due to thermal conduction, $P_{b}$ is the rate of heat loss per unit volume due to blood flow, and $c$ is the specific heat. If before the exposure a steady-state condition exists such as $P_{m}=P_{c}+P_{b}$, then during the initial period of exposure we have:

$$
\frac{\Delta T}{\Delta t}=\frac{\mathrm{SAR}}{c}
$$

Accordingly, SAR can be determined from measurements of an increase in the tissue temperature over a short period of time following the exposure. For tissue phantoms and tissues in vitro, several methods of SAR determination are based on thermal measurements and utilization of equations (14) and (15). More generally, from a macroscopic point of view, thermal effects resulting from the absorption of EM waves inside biological materials are described in terms of the bioheat equation. ${ }^{3}$

\section{BIOHEAT EQUATION}

To determine the temperature rise once electric fields are known, one must first choose an appropriate continuum model of the evolution of temperature in a biological system. The temperature rise within a biological system depends on the spatial distribution of the EM fields, the thermal constitutive parameters of the biological system, and the governing thermodynamics. ${ }^{106}$ The transfer of thermal energy in living tissues is a complex process involving multiple mechanisms including blood perfusion, metabolic heat generation, conduction, convection, 
radiation, evaporation, and external interactions such as EM radiation from other sources.

Successful thermal treatment of tumors requires understanding the attendant thermal processes in both diseased and healthy tissue. Accordingly, it is essential for developers and users of thermal therapy equipment to predict, measure, and interpret correctly the tissue thermal and vascular response to heating. Modeling of heat transfer in living tissues is a means towards this end. Due to the complex morphology of living tissues, such modeling is difficult and requires some simplification of assumptions ${ }^{107}$ and, as a first step, mathematical techniques for solving Maxwell's equations for reasonably accurate representations of the actual objects. Because of the mathematical difficulties encountered in this calculation, a combination of techniques is used for the computation of the absorbed EM power distribution in the tissue. Each technique gives information over a limited range of parameters depending on the chosen model. Such modeling is essential because it allows optimal source configurations and provides results that will serve as input data for developing thermal models. Various models such as blocks, spheroids, ellipsoids, and cylinders with suitable EM and thermal characteristics have been used in many studies ${ }^{49,51,52,108-111}$ to represent different parts of the human body such as the head and limbs. Recently, magnetic resonance imaging (MRI)-based anatomically accurate models have been used in conjunction with FDTD-based solutions of Maxwell's equations. ${ }^{112-116}$

\section{III.A. Pennes Model}

An extremely important study in the modeling of bioheat transfer was reported over half a century ago by Pennes. ${ }^{117}$ Pennes developed a cylindrical model of a human limb to simulate the forearm but later generalized it to any limb. The model considered all the properties essential for the conduction, thermal storage, and environmental exchange terms to refer to the tissue while he referred to the blood properties in the blood perfusion system. Pennes suggested a model in which the net heat transfer from blood to tissue was proportional to the temperature difference between the arterial blood entering the tissue and the venous blood leaving the tissue. Pennes' principal theoretical contribution was his suggestion that the rate of heat transfer between blood and tissue is proportional to the product of the volumetric perfusion rate and the difference between the arterial blood temperature and the local tissue temperature. When most researchers apply Pennes model, 
they assume that the temperature of venous blood is in equilibrium with the local tissue temperature and that the arterial blood temperature $T_{a}$ is constant. The Pennes model describes blood perfusion with acceptable accuracy if no large vessels are nearby. ${ }^{107}$

\section{Bioheat Equation}

Following Pennes' suggestion, the thermal energy balance for perfused tissue is expressed in the following form:

$$
\rho c \frac{\partial T}{\partial t}=k \frac{\partial^{2} T}{d x^{2}}+k \frac{\partial^{2} T}{d y^{2}}+k \frac{\partial^{2} T}{d z^{2}}+\omega_{b} c_{b} \rho_{b}\left(T_{a}-T\right)+Q_{m}+Q_{y}(x, y, z, t)
$$

where $T=T(x, y, z, t)$ is the temperature elevation $\left({ }^{\circ} \mathrm{C}\right), \rho$ and $\rho_{b}$ are the density of tissue and blood, respectively $\left(\mathrm{kg} / \mathrm{m}^{3}\right), c$ is the specific heat of the tissue $(\mathrm{J} / \mathrm{kg} / \mathrm{K}), k$ is the tissue thermal conductivity $(\mathrm{W} / \mathrm{m} /$ $\mathrm{K}), \omega_{b}$ is the blood volumetric perfusion rate $\left(\mathrm{kg} / \mathrm{m}^{3} / \mathrm{s}\right), c_{b}$ is the specific heat of blood $(\mathrm{J} / \mathrm{kg} / \mathrm{K}), T_{a}=T_{a}(x, y, z, t)$ is the ambient temperature of perfusing blood $\left({ }^{\circ} \mathrm{C}\right) . Q_{m}$ is the heat generation in the body, that is, the heat generated by the normal processes in the body $\left(\mathrm{W} / \mathrm{m}^{3}\right)$, and $Q_{r}$ is the regional heat delivered by the source $\left(\mathrm{W} / \mathrm{m}^{3}\right)$.

The term $\omega_{b} c_{b} \rho_{b}\left(T_{a}-T\right)$ in Equation (16) models the perfusion heat loss. Vascular tissues generally experience increased perfusion as temperature increases. The above term is always considered in cases of tissues with a high degree of perfusion, such as liver. Regarding cardiac ablation, the perfusion heat loss is incorporated in some models, but is generally ignored since its effect is negligible. ${ }^{118}$ In general, $\omega_{b} i s$ assumed to be uniform throughout the tissue. However, its value may increase with heating time because of vasodilatation and capillary recruitment.

Spatially distributed heating occurs in skin exposed to penetrating, dissipative radiation such as microwave, ultrasound, and laser light. ${ }^{119}$ These heating methods often involve an exponentially decaying power transmission accompanied by reflection at the interface of regions with different electrical properties. For a uniform plane wave incident normally upon the skin surface, with a layer of air included to model the reflection at the skin/air interface, the average absorbed power density $Q_{r}$ is given by:

$$
Q_{r}=\frac{1}{2} \sigma|E|^{2}
$$


At the frequencies employed in $\mathrm{RF}$ ablation $(300 \mathrm{kHz}-1 \mathrm{MHz})$ and within the area of interest (it is known that the electrical power is deposited within a small radius around the active electrode), the tissues can be considered purely resistive because the displacement currents are negligible. For this reason, a quasi-static approach is usually employed to resolve the electrical problem. Then, $Q_{r}=J E$, where $J$ is the current density $\left(\mathrm{A} / \mathrm{m}^{2}\right)$.

In order to build a theoretical model, the values of the basic physical characteristics have to be set for all the material of the model: mass density $(\rho)$, specific heat $(c)$, thermal conductivity $(k)$, and electrical conductivity $(\sigma)$. In general, it is difficult to measure tissue properties because they are spatially, temporally, and even temperature dependent. The above properties, however, are considered to be isotropic and their values are usually taken from the scientific literature as shown in Table I. ${ }^{120-123}$

\begin{tabular}{lc}
\hline \multicolumn{2}{c}{ Table I. Approximate Value of Biological Tissue Constants } \\
\hline Properties & Value \\
\hline Arterial temperature $T_{a}\left({ }^{\circ} \mathrm{C}\right)$ & 37 \\
Thermal conductivity of tissue $\mathrm{k}(\mathrm{W} / \mathrm{mK})$ & 0.488 \\
Mass density of tissue $\rho\left(\mathrm{kg} / \mathrm{m}^{3}\right)$ & 1000 \\
Specific heat capacity of tissue c $(\mathrm{J} / \mathrm{kg} / \mathrm{K})$ & 3590 \\
Specific heat capacity of blood c $(\mathrm{J} / \mathrm{kg} / \mathrm{K})$ & 3840 \\
Blood perfusion rate $\omega_{b}\left(\mathrm{~kg} /\left(\mathrm{m}^{3} \mathrm{~s}\right)\right.$ & 0.5 \\
\hline
\end{tabular}

Prediction of heat transport has long been carried out by both analytical and numerical methods. The temperature rise for constant (temperature independent) perfusion has been predicted by traditional analytical methods based on Equation (16), which can be solved analytically for simple geometries or by FEM or finite-difference method (FDM) for more realistic, complicated tissue geometry. ${ }^{124}$ Equation (16) has been used in a wide range of applications to describe heat transport in blood-perfused tissues and solved by a variety of methods. An adaptive FEM was used to optimize the nonlinear bioheat equation for optimizing regional hyperthermia. ${ }^{125}$ Two-dimensional biothermal models of ultrasound applicators based on the bioheat equation were solved by FDM. ${ }^{126}$ An analytical solution of the three-dimensional Pennes equation is presented in $\mathrm{Liu}^{123}$ using multidimensional Green function. The boundary element and FDM have also been used to solve the bioheat equation. ${ }^{127-130}$ Closed-form analytical solutions to 
the bioheat transport problems with space and transient heating were reported using Green's function method. ${ }^{131}$

\section{Limitations}

One advantage of Pennes bioheat equation is its simplicity. Given the relevant properties and perfusion rates, it becomes fairly easy to solve for tissue temperature as a function of spatial location and time. It is well known that the Pennes' perfusion source term overestimates the actual blood perfusion effect in tissue in two ways. The first limitation is that it considers that all the heat leaving the artery is absorbed by the local tissue and there is no venous rewarming. ${ }^{132}$ Brinck and Werner ${ }^{133}$ and Wissler ${ }^{134}$ suggested a correction coefficient that is less than unity and accounts for venous rewarming that should multiply the perfusion term. A correction coefficient that is close to zero implies a significant countercurrent rewarming of the paired vein and a coefficient of unity implies no rewarming. Weinbaum et al. ${ }^{135}$ showed that for most muscle tissues, the correction coefficient varies between 0.6 and 0.8. A second limitation of the Pennes perfusion source term is that the arterial temperature is assumed to be equal to the body core temperature. The alternative to the Pennes equation is to employ a decidedly more complex model that explicitly describes heat exchange between vessel pairs. Keller and Seiler ${ }^{136}$ proposed such a model, which includes both countercurrent heat exchange between vessel pairs and thermal equilibration in the capillary bed.

Pennes equation was further simplified to a first approximation by Goldberg et al., ${ }^{137}$ who described the basic relationship guiding thermal ablation-induced coagulation necrosis as follows: coagulation necrosis $=$ energy deposited $\times$ local tissue interactions - heat loss. On the basis of this equation, several strategies have been employed to increase the amount of coagulation necrosis by improving tissue-energy interactions during thermal ablation, including increasing energy deposition or modulating tissue interactions or blood flow. ${ }^{138}$

\section{Analysis Based on Pennes Equation}

To better understand the heating performance of a heating probe on living tissues, analysis of the temperature response based on Pennes equation may be necessary. For simplicity, the shape of the heating probe tip can be approximated as a sphere (Figure 1). Equation (16) can be transformed as: 


$$
\rho c \frac{\partial T}{\partial t}=\frac{k}{r} \frac{\partial^{2}(r T)}{d r^{2}} \omega_{b} c_{b} \rho_{b}\left(T_{a}-T\right)+Q_{m}+Q_{r}(x, y, z, t)
$$

Considering the clinical situation, several assumptions may be made. Firstly, the initial tissue temperature is treated as uniform at $37^{\circ} \mathrm{C}$. Secondly, the heating area is $n$ times the radius of the probe. Outside this range, the tissue temperature will not be affected by heating and stays at a constant value of $37^{\circ} \mathrm{C}$. Thirdly, the temperature at the tip of the probe will be kept constant at the desired heating value, for example, at $100^{\circ} \mathrm{C}$. Based on these assumptions, the boundary and initial conditions for Equation (18) can be expressed as: ${ }^{139}$

$$
\begin{array}{ll}
T=T_{p} & r=R_{o} \\
T=T_{c} & r=n R_{o} \\
T=T_{c} & t=0
\end{array}
$$

where $R_{\mathrm{o}}$ is the probe sphere radius and $r$ is radial position.

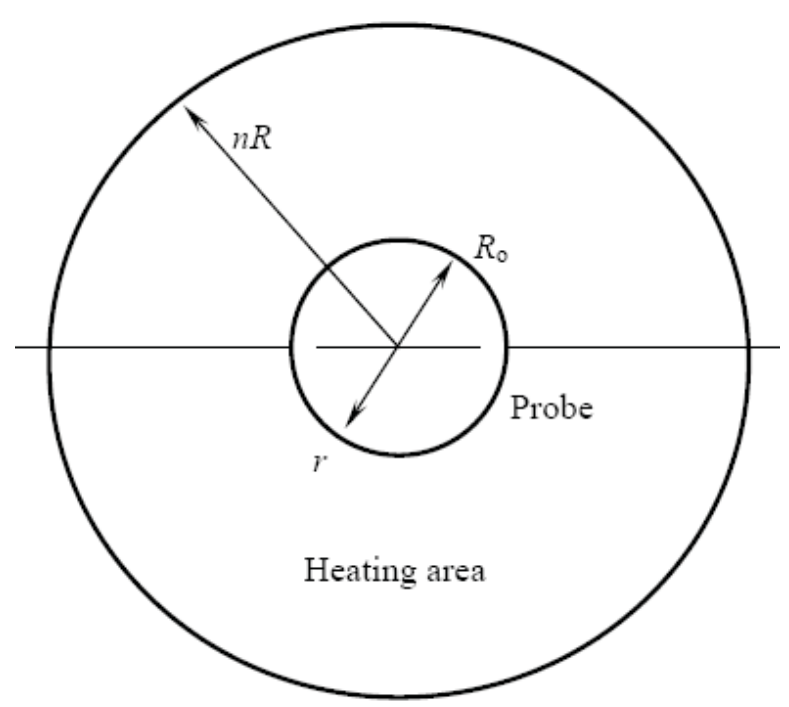

FIGURE 1. Geometry of the heating area of the tissue. 


\section{III.B. Wissler Model}

An important feature of Pennes' approach is that his microscopic thermal energy balance for perfused tissue is linear, which means that the equation is amenable to analysis by various methods commonly used to solve the heat-conduction equation. Therefore, it has been adopted by many researchers who have developed mathematical models of heat transfer in the human. ${ }^{140}$ Wissler ${ }^{141,142}$ modified the model of Pennes to obtain a model of the entire human body. This model subdivided the body into six elements: head, torso, two arms, and two legs. Each of these elements was assumed to have the following characteristics: a uniformly distributed metabolic heat generation, a uniformly distributed blood supply, a composition of homogeneous materials, and a geometry of isotropic cylinders. This model has been upgraded for active physiological factors in thermoregulation, such as regional perfusion rates. ${ }^{143}$

\section{III.C. Stolwijk Model}

The entire human body was modeled by Stolwijik and associates at the John B. Pierce Foundation Laboratory. ${ }^{144}$ The model was composed of three cylindrical segments, one each for the head, trunk, and extremities. The trunk was divided into three concentric layers: skin, muscle, and core. The head and extremities were divided into only two concentric layers: skin and core. For thermal modeling purposes, the authors suggested the concept of the body as composed of a controlled system and a controlling system. The controlled system can be modeled by a transient heat-conduction model with internal heat generation (metabolism) and heat dissipation. The controlling system provides physiologically relevant thermal boundary conditions in order to maintain homeothermy. The heat transfer equation simulating this model is:

$$
\rho c \frac{\partial T}{\partial t} T=\nabla \cdot k \nabla T+\left(\frac{1}{V}\right)\left(Q_{m}-Q_{s}-Q_{r e s}\right)
$$

where $Q_{s}$ represents the evaporative heat dissipation in the skin and $Q_{r e s}$ is the respiratory heat loss in the lungs. The model consists of 15 cylindrical segments and a sphere for the head, with each segment divided into four concentric layers: core, muscle, fat, and skin. This model was later expanded by Stolwijk and Cunningham ${ }^{145}$ and Stolwijik ${ }^{146,147}$ 
to include six parts of the human body: head, trunk, arms, hands, legs, and feet.

\section{III.D. Weinbaum - Jiji (W-J) Model}

Weinbaum and $\mathrm{Jiji}^{98}$ utilized the hypothesis that small arteries and veins are parallel and the flow direction is countercurrent resulting in counterbalanced heating and cooling effects. This kind of tissue vascularization would cause the isotropic blood perfusion term in the Pennes equation to be negligible and would cause the tissue to behave as an anisotropic heat transfer medium. Therefore, Weinbaum and Jiji ${ }^{98}$ modified the thermal conductivity of the Pennes equation by means of an effective conductivity related quadratically to blood perfusion rate that is affected by the dimensions and the directions of the vessels. Weinbaum and $\mathrm{Jiji}^{98}$ used this work and assumed a linear relation between the effective thermal conductivity and the blood perfusion rate to determine the increase in the thermal conductivity in a perfused tissue. They reported an 11\% increase in the thermal conductivity. They suggested that in addition to a "temperature map", a "perfusion map" within the heated volume should be monitored routinely throughout the thermal therapy process since the local value of perfusion can vary substantially within a few centimeters. Song et al. ${ }^{148}$ demonstrated that a tissue that exhibits only a small increase in the thermal conductivity due to countercurrent convection in its vasoconstricted state (narrowing of the blood vessels) can exhibit more than a five-fold increase in the thermal conductivity in its vasodilated state (during relaxation of the muscle).

Weinbaum et al. ${ }^{135}$ developed a new model for muscle tissue heat transfer using Myrhage and Eriksson's ${ }^{149}$ description of a muscle tissue cylinder surrounding secondary vessels as the basic heat transfer unit. This model provides a rational theory for the venous return temperature for the perfusion source term in a modified Pennes bioheat equation and greatly simplifies the anatomical description of the microvascular architecture required in the W-J model. An easy-to-use closed-form analytical expression has been derived for the difference between the inlet artery and venous return temperatures using a model for the countercurrent heat exchange in the individual muscle tissue cylinders. The perfusion source term calculated from this model is found to be similar in form to the Pennes' source term except that there is a correction factor or efficiency coefficient multiplying the Pennes' term, which rigorously accounts for the thermal equilibration of the returning vein. 
This coefficient is a function of the vascular cross-sectional geometry of the muscle tissue cylinder.

Wissler ${ }^{150}$ pointed that the Weinbaum and Jiji's ${ }^{98}$ model assumes the mean temperature in the neighborhood of an artery/vein to be the arithmetic mean of the arterial and venous blood at the point of entry and that the temperature of blood draining into veins from capillaries and small veins is equal to the temperature of venous blood at the point of entry, assuming there is very little heat transfer between thermally significant artery-vein pairs and the tissue. Wissler ${ }^{150}$ indicated that these assumptions are questionable and the model suggested by Weinbaum and Jiji ${ }^{98}$ was derived for a subcutaneous region (tissues under the skin). Wissler ${ }^{150}$ denoted that the muscle and skin are rather different and a formulation appropriate for one may not be applicable for another biological tissue.

\section{III.E. Baish Model}

Baish ${ }^{151}$ presented a new bioheat transfer model for perfused tissue. He considered simulation of a realistic vascular tree containing all thermally significant vessels in a tissue using a physiologically based algorithm. Baish's model is based on solving the convection of the blood coupled to the three-dimensional conduction in the extravascular tissue while accounting for a statistical interpretation of the calculated temperature field. This model illustrates the dependence of the temperature distribution on the flow rate and the vascular geometry. Baish ${ }^{151}$ also illustrated that the Pennes formulation accurately predicts the mean tissue temperature except when the arteries and veins are in closely spaced pairs. Baish's model is useful for fundamental studies of tissue heat transport.

\section{III.F. Applications of Bioheat Transfer Models}

Knowledge of heat transfer in biological bodies has many therapeutic applications involving either decrease or increase of temperature and often requires precise monitoring of the spatial distribution of thermal histories that are produced during a treatment protocol. ${ }^{131}$ Unlike the prediction of the electric field, for which an appropriate continuum physical model may exist, no clear compromise exists for a suitable mathematical model to predict heating patterns in biological objects. ${ }^{106}$ Biomedical engineers have attempted to model accurately bioheat transfer in tissues since it is the basis for the human thermotherapy ${ }^{152}$ 
and the human thermoregulation system. ${ }^{153}$ Table II summarizes the characteristics of the bioheat transfer models discussed above.

\begin{tabular}{ll}
\hline Table II. Summary of Bioheat Transfer Models \\
\hline Bioheat Transfer Model & Characteristics \\
\hline Pennes & $\begin{array}{l}\text { Simple; accounts for the ability of tissue to remove } \\
\text { heat by both passive conduction (diffusion) and } \\
\text { uniform perfusion of tissue by blood. } \\
\text { Weinbaum and Jiji }\end{array}$ \\
$\begin{array}{l}\text { It is good when arteries and veins are close } \\
\text { leading to negligible blood perfusion. }\end{array}$ \\
$\begin{array}{l}\text { Wissler } \\
\text { model. }\end{array}$ \\
\hline
\end{tabular}

Lang et al. ${ }^{154}$ described an optimization process specially designed for regional hyperthermia of deep-seated tumors in order to achieve desired steady-state temperature distributions. A nonlinear threedimensional heat transfer model based on temperature-dependent blood perfusion was applied to predict the temperature. Using linearly implicit methods in time and adaptive multilevel finite elements in space, the investigators were able to integrate efficiently the instationary nonlinear heat equation with high accuracy. Temperature distributions for two individual patients calculated on coarse and fine spatial grids were compared.

Liu et al. ${ }^{155}$ used Pennes bioheat transfer equation to model the transient heat transfer inside the canine prostate during transurethral microwave thermal therapy. By incorporating the specific absorption rate of microwave energy in tissue, a closed-form analytical solution was obtained. Good agreement was found between the theoretical predictions and in-vivo experimental results. Effects of blood perfusion and cooling at the urethral wall on the temperature rise were investigated within the prostate during heating. The peak intraprostatic temperatures attained by application of 5-, 10-, or 15-W microwave power were predicted to be $38^{\circ} \mathrm{C}, 41^{\circ} \mathrm{C}$, and $44^{\circ} \mathrm{C}$, respectively. Zhu and Diao ${ }^{156}$ used the Pennes equation to simulate the steady-state temperature distribution within the brain after head injury. Also, Deng and Liu ${ }^{131}$ used the equation to study analytically the effect of pulsative blood perfusion on the tissue temperature. Wainwright ${ }^{157}$ applied Pennes thermal model and found the final steady-state temperature rise in the brain for a 0.25 W antenna at frequencies of $900 \mathrm{MHz}$ and $1800 \mathrm{MHz}$ to be as high as 
$0.1^{\circ} \mathrm{C}$. However, other EM devices could produce greater heating and there is the possibility that nonuniform heating could produce local, higher temperature rises.

\section{THERMAL THERAPY PLANNING SYSTEM}

Because of limited thermometry, knowledge about the temperature distributions achieved can be obtained through simulation of treatment by computer predictions and planning of individual patient therapy. This process, which is called thermal therapy planning system (TTPS), is a large and complex system that provides a complete three-dimensional SAR and temperature distribution in the treatment area. The TTPS must address a complex relation between heating system, perfusion, discrete vasculature, and anatomy. ${ }^{93}$

\section{IV.A. Objectives and Requirements}

The aim of TTPS is to determine control parameters that result in a favorable temperature distribution. In a favorable distribution, the heating should be concentrated in the tumor and hot spots should be avoided in healthy tissues. Both the high-resolution FDTD code and the integral methods using FEM act as a core of absorbed power computations needed in the TTPS. ${ }^{158}$

The thermal therapy planning system will ultimately provide information about the actual temperature distributions obtained and thus the tumor control probabilities to be expected. This will improve understanding of the clinical results of thermal therapy and will greatly help both in optimizing clinical heating technology and in designing optimal clinical trials. ${ }^{93}$ While a great deal of effort is applied toward solving the technical problems associated with modeling clinical thermal therapy treatments, especially in estimating the power deposition, other effort should be applied to using the modeled power depositions as inputs to estimate the thermal-therapy-induced three-dimensional temperature distributions. ${ }^{159}$ The type of treatment planning programs that have already been developed for radiotherapy must be developed for more complex requirements of both prospective and retrospective study of thermal dosimetry in clinical thermal therapy. ${ }^{16}$

As a comprehensive process, treatment planning includes:

1. methods for the determination of the target volume (target definition), 
2. segmenting medical image data and generating a threedimensional model of the target and normal tissue structures,

3. calculating the absorbed power distribution,

4. assigning tissue thermal properties,

5. virtually placing heat sources into the three-dimensional structure,

6. measuring SAR patterns,

7. calculating heat transfer through the solution of bioheat equation during treatment from the power deposition to provide temperature distribution as a function of time, and finally

8. estimating three-dimensional dose calculation. ${ }^{27,93,152}$

An important feature of a thermal model must be its capability to describe the complex heat transfer related to the vasculature. ${ }^{93,160,161}$

Based on the results of temperature calculation, optimal applicator parameters are determined, that is, amplitudes and phases of the signals sent to the antennas. In the case of the nonlinear bioheat equation, temperature calculation and optimization are coupled via a fixed-point iteration. An extensive set of visualization and evaluation tools must complete a treatment planning system. ${ }^{162}$ For treatment planning or post-treatment evaluation of completed therapy, a more detailed study of the dielectric parameters, anatomical structures, and blood perfusion mechanism is necessary. Monitoring and control of temperatures during treatment requires advanced thermal imaging.

\section{IV.B. Developments in TTPS}

Development of the first two-dimensional TTPS to the most advanced three-dimensional models, which have dynamic nonuniform grid generation and conformal three-dimensional FDTD schemes supporting high resolution models at critical structures, are expected to allow a priori selection of the optimal energy deposition or temperature distribution. ${ }^{163}$ Lagendijk ${ }^{93}$ briefly described the state of the art in thermal therapy technology, followed by an overview of the developments in TTPS. The review highlights the significant problems encountered with heating realistic tissue volumes and shows how treatment planning can help in designing better heating.

Optimization techniques based on SAR are more widely applied than temperature-based techniques in treatment planning systems for thermal therapy. ${ }^{164}$ Das et al. ${ }^{165}$ and Paulsen et al. ${ }^{166}$ have developed FEM-based treatment planning systems, while Nadobny et al., ${ }^{167}$ 
Gellermann et al., ${ }^{168}$ Van De Kamer et al., ${ }^{169}$ and Van den Berg et al. ${ }^{170}$ have developed FDTD-based system for predicting the SAR produced by the Sigma 60 applicator in the pelvic region of patient model.

Clegg et al. ${ }^{159}$ presented a case report of a patient treated with thermal therapy at the Duke University Medical Center where numerical modeling of the EM power deposition was used to plan the treatment. The modeled power was used as input to reconstruct retrospectively the transient three-dimensional temperature distribution. The modeled power deposition indicated the existence of an undesirable region of high power in the normal tissue. Using the computed three-dimensional transient temperature distribution, the thermal therapy thermal dose was computed.

Treatment planning systems for superficial thermal therapy are still lagging behind those for deep regional heating, although superficial thermal therapy is easier to control than deep heating due to the proximity of the heating applicator to the treatment object. Kumaradas and Sherar ${ }^{84}$ presented a new numerical model of microwave heating that is designed to aid in the development of new applicators for superficial heating. The model, which is based on FEM, was successfully verified against previously published measurements of heating from a modified water bolus attached to a conventional waveguide applicator.

Temperature-based optimization is clinically more relevant than SAR optimization since hot spots will correspond to temperature rather than to SAR and several important factors like perfusion, conduction, and bolus cooling are not taken into account when optimizing SAR distribution. ${ }^{171,172}$ For adequate treatment planning, it is necessary to perform simulations at high resolutions. At low resolution, small anatomical structures can be modeled incorrectly or even missed, which can result in an erroneous prediction of hot spots. ${ }^{169,171,172}$ Kok et al. ${ }^{172}$ applied hyperthermia treatment planning combined with high resolution temperature-based optimization to improve hyperthermia treatment of patients with esophageal cancer. The optimization was based on steady-state temperatures and accurate temperature calculations with uncertainties in thermal properties and perfusion values.

\section{IV.C. Thermal Monitoring}

Although treatment planning can be used to prescribe the location of the heat source (for examples, electrode or antenna), it is unlikely to replace the need for active monitoring of thermal dose delivery during treatment. Deviations from predicted temperatures could be caused by a number of 
factors including unpredictable and/or changing blood flow or changes in the electrical or thermal properties of tissue during coagulation, where these changes are not fully accounted for in the treatment plan. ${ }^{27}$ Full three-dimensional on-line thermal dosimetry would be the ideal; of particular promise in this regard is the use of magnetic resonance thermometry. ${ }^{173}$ Invasive and non-invasive procedures to achieve treatment monitoring are discussed in the following section.

\section{DEVELOPMENT OF THERMOMETRY}

Temperature refers to a certain standard of reference. Historically, heat emanating from the body was estimated by the use of hands, a practice that remained well into the sixteenth and seventeenth centuries. Temperature is measured with thermometers that may be calibrated to a variety of temperature scales. A thermometer is a device with a measurable output that changes with temperature in a reproducible manner.

Thermometry developed slowly from Galileo's experiments. Florentine and Venetian glassblowers in Italy made sealed glass containers of various shapes that were tied onto the body surface. The rise or fall of small leads or seeds within the fluid in the container assessed the temperature of an object. Such measurement had no scale. Huygens, Roemer and Fahrenheit proposed the need for a calibrated scale in the 17 th and early 18 th centuries. Celsius proposed a centigrade scale based on ice and boiling water. He suggested that on his scale boiling water should be zero and melting ice should be 100. The Danish biologist Linnaeus in 1750 proposed the reversal of this scale, as it is known today. ${ }^{174}$

Professor Carl Wunderlich of Leipzig in 1868 advanced the use of thermometry in medicine with the first set of temperature charts on individual patients with a wide range of diseases. Clinical experience with this type of thermometer exceeds 130 years. This thermometer has a limited scale around the normal internal body temperature of $37^{\circ} \mathrm{C}$ or $98.4^{\circ} \mathrm{F} .{ }^{174,175}$ Normal body temperature was considered to be $37^{\circ} \mathrm{C}$, based on a study of axillary temperatures in adults, incorporating over 25000 readings with mercury-in-glass thermometers in $1868 .{ }^{176}$ The advantages of mercury-in-glass thermometers are that accuracy is verified by calibration, they do not rely on battery power, and they are capable of providing reliable clinical readings regardless of the environmental conditions, providing that clinical measurement

technique is carefully implemented. The disadvantages of these 
thermometers are long reading times and that they cannot be used orally in uncooperative patients or young children. ${ }^{175}$

The use of liquid crystals became another technique of displaying skin temperature. Cholesteric esters can have the property of changing color with temperature, as was established by Lehmann in 1877 . The practical application involved elaborate panels that encapsulated the crystals and were applied to the surface of the skin, but due to a large area of contact, they affected the temperature of the skin.

A major development in the early 1940s was the first electronic sensor for infrared radiation that could be used for thermal imaging. This was made from indium antimonide and mounted at the base of a small Dewar vessel to allow cooling with liquid nitrogen. The first medical images taken with a British prototype system, the Pyroscan, were made at Middlesex Hospital in London, and the Royal National Hospital for Rheumatic Diseases in Bath, from 1959 to 1961. ${ }^{174}$ The basis for this device was work of the astronomer Sir William Herschel in Bath. He discovered infrared radiation when trying to measure the heat of the separate colors of the rainbow spectrum cast on a table in a darkened room. He found the highest temperature to fall beyond the red end, which he reported to the Royal Society as Dark Heat in 1800. His son, Sir John Herschel, who was interested in photography, recorded the heating rays on the infrared side of red by creating an evaporograph image using carbon suspension in alcohol. This image was named a thermogram.

Recently, there has been a move away from glass thermometers in many countries, giving rise to a more disposable sterile thermocouple and radiometers for middle ear temperature. ${ }^{174}$

\section{INVASIVE TECHNIQUES}

Clinical thermometry can be performed (minimally) invasively and noninvasively. Invasive thermometry methods require implantation of catheters in tissues. This ensures good thermal contact with tissues, but these methods have been questioned over the years. The low acceptance by patients and physicians was a limiting factor when many patients were to be given thermal treatment in randomized studies. Problems encountered include the time-consuming invasive placement of the catheters with the risk of hemorrhage and acute neurological side effects. Additionally, infections and a variety of discomforts were observed. ${ }^{26}$

The temperature meters used for invasive thermometry are highly 
accurate with high temporal and spatial resolution. For high-quality thermometry, the temperature probes must be placed at the critical locations. Traditionally, invasive thermometry has been used to measure temperatures in a target region. However, it is time consuming, uncomfortable, and risky for the patient. Invasive thermometry can be accomplished generally by three types of electrodes: thermocouple sensors, thermistors, and optical fiber thermometers. ${ }^{3}$ For hyperthermia, international guidelines recommend invasive intra-tumoral temperature measurements, ideally along two-to-three orthogonal scanning lines. ${ }^{39}$ It is recommended to register temperature position scans every 5-10 min. Either index temperatures averaged over time or thermal dose parameters accumulated over time are derived from these data. ${ }^{26}$ These intra-tumoral measurements have been successfully correlated with clinical endpoints. ${ }^{177-179}$

\section{VI.A. Thermocouple}

A thermocouple is a sensor that measures temperature. It consists of two different types of metals joined together at one end. When the junction of the two metals is heated or cooled, a voltage is created that can be correlated to the temperature. Thermocouples are normally made from special thermocouple alloy wire that is joined at one end by a weld or other mechanical connection. The thermocouple has been used widely to measure temperature in various applications. This thermometry principle is based on the Seebeck effect, discovered by Thomas Johann Seebeck in $1821 .^{3}$

Thermocouples are most useful when low mass or differential temperature measurements are required. They must be calibrated in situ because the entire length of the wire contributes to the output voltage if it traverses a temperature gradient. Variations in wire composition, homogeneity, or even mechanical strain can affect the temperature reading. ${ }^{180}$

There are two types of thermocouples: a sheath type and a protectedtube type. Sheathed thermocouple probes are available with one of three junction types: grounded, ungrounded, or exposed. At the tip of a grounded junction probe, the thermocouple wires are physically attached to the inside of the probe wall. This results in good heat transfer from the outside, through the probe wall to the thermocouple junction. In an ungrounded probe, the thermocouple junction is detached from the probe wall. Response time is slower than the grounded style, but the ungrounded style offers electrical isolation. The thermocouple in the exposed junction style protrudes out of 
the tip of the sheath and is exposed to the surrounding environment. This type offers the best response time, but is limited in use to dry, noncorrosive, and nonpressurized applications.

The thermocouple of the protected-tube type consists of a protected tube, a terminal box, and a glass that insulates the thermocouple wire. The outside dimension is of the order of 3-30 $\mathrm{mm}$. In general, the sheath type has rapid response with respect to temperature change because the sheath diameter is relatively narrow and the inside of the sheath is filled with inorganic insulation material when compared to the protected-tube type. ${ }^{3}$

An advantage of thermocouples is the possibility of combining multiple sensors in one probe. A disadvantage of thermocouples is their susceptibility to EM disturbances. Thermocouples are very difficult to use as low temperature thermometers in the presence of magnetic fields as the thermoelectric power depends on both the temperature and the magnetic field. ${ }^{180,181}$

\section{VI.B. Thermistor}

The most popular and widely available temperature sensor for low temperature is a resistor. A temperature sensor called a thermistor is a thermally sensitive resistor that exhibits a change in electrical resistance with a change in its temperature. There are two main resistor classifications: positive temperature coefficient (PTC) and negative temperature coefficient (NTC). Positive temperature coefficient resistors are typically a pure metal such as platinum, copper, or nickel, or a pure metal with small impurities such as rhodium-iron or platinum-cobalt. Semiconductors such as germanium have NTC behavior. ${ }^{180}$ Thermistors typically work over a relatively small temperature range, compared to other temperature sensors, and can be very accurate and precise within that range. ${ }^{182}$

\section{VI.C. Optical Fiber Thermometer}

Sometimes it is better to use noninductive optical fiber to measure temperature in a strong EM field environment as in thermal therapy treatments. In 1987, the first laser-based emissivity measuring infrared thermometer was introduced. This instrument is currently in worldwide use in industrial and research applications. In 1990, a fiber-optic sensor version was developed. This provided broader temperature measurement ranges; smaller target sizes; lower cost; and most importantly, flexibility of sensor head size, shape, and materials. The optical fiber thermometer 
has a simple thermosensor attached to the tip of an optical fiber that is composed of a phosphor capable of excitation by a light-emitting diode (LED). The tip of the optical fiber is attached to the measured object and a pulse of the infrared (IR) excitation light at a wavelength of $940 \mathrm{~nm}$ is applied. This applied pulse is converted into visible light at a wavelength of $550 \mathrm{~nm}$, simultaneously it is modulated by the temperature. After the IR pulse is applied, there is an afterglow for a while, even if the exciting light is cut off. The afterglow is dependent on temperature. Therefore, the temperature can be calculated by sequential sampling of the quantity of afterglow in a time series and summing it, after the search of the afterglow integral luminance. ${ }^{3}$

Currently, temperature sensors placed on the skin surface and inside invasively placed catheters within the treatment volume are the only reliable means available for acquiring detailed thermometry data. Manual mapping of various types of temperature sensors through phantoms, animal, and human tissues has been employed in order to characterize temperature distributions during treatments and to determine applicator SAR patterns. ${ }^{183,184}$ Commercially available thermometry equipment is inadequate in providing the thermometry information needed to properly control these applicators at a reasonable cost. One method of increasing the amount of accessible temperature data is by spatially multiplexing the available thermometry by automatically scanning the sensors through catheters placed within the treatment field. Several investigators have used invasive techniques to measure temperature elevation during thermal therapy. ${ }^{182,185} \mathrm{~A}$ list of invasive temperature measuring devices is given in Table III.

\begin{tabular}{ll}
\hline Table III. Invasive & Thermometry Devices \\
\hline Type & Description \\
\hline Thermistors & $\begin{array}{l}\text { Strong interaction with EM fields. Accurate when not used } \\
\text { in EM fields. }\end{array}$ \\
Thermocouples & $\begin{array}{l}\text { Multiple junction probes possible. Filtering and shielding } \\
\text { required. Microjunction preferable. }\end{array}$ \\
Fiber Optics & $\begin{array}{l}\text { No interaction with EM fields. Frequent calibration } \\
\text { required. }\end{array}$ \\
\hline
\end{tabular}

\section{NONINVASIVE TECHNIQUES}

Medical imaging is the general name for the methodology in which a 
biological subject's structure or function, which is usually visible, is visualized with physical media such as X-rays for the diagnosis and treatment of diseases. ${ }^{34}$ Doctors have imaged the human body with Xrays since the early 1900 s. Since then, medical imaging has been an indispensable element of medical care; in particular, following the creation of the X-ray CT in $1973 .{ }^{186}$ However, X-rays have important disadvantages including the exposure of the subject to ionizing radiation. Given this fact and probably other issues related to the quality of Xray images, the idea of thermal detection had obvious appeal. The first report of the use of temperature measurements to diagnose cancer was apparently published by Lawson ${ }^{187}$.

Noninvasive measurement of the temperature distribution within the body is an attractive concept because of the potential of visualizing three-dimensional temperature distribution during thermal therapy. Some techniques are currently in clinical use, while others are still in the preclinical or experimental stage. ${ }^{188}$ Thermal imaging is classified into two main types: active and passive. Active methods for thermal imaging expose the region of interest to energy. The energy is modulated by the tissue temperature and analyzed to retrieve information on the temperature within the body. Passive methods estimate the temperature within the body by analyzing the spontaneously radiated energy from it. ${ }^{38}$

In general, noninvasive thermometry in clinical thermal therapy remains a distant goal, although developments in microwave radiometry may lead to systems with suitable spatial, temporal, and temperature resolution for use in superficial treatments. Today, noninvasive thermometry can be achieved using several different physical approaches: impedance tomography, ${ }^{166}$ active and passive microwave imaging, ${ }^{189} \mathrm{CT}$, laser, infrared, ultrasound, and MRI techniques. ${ }^{16,190}$

Of all these different techniques, ultrasound and MRI are the most advanced for acquiring functional information and are widely used clinically, mainly in experimental settings for thermal therapy. However, morphological information is widely acquired with X-ray imaging and MRI. Therefore, each modality has its own strengths and the different modalities compete and complement each other.

\section{VII.A. Ultrasound}

The history of ultrasound imaging is much more recent than that of X-ray imaging. After the pioneering work of Wild and Reid in the $1950 \mathrm{~s},{ }^{191}$ the image quality of medical ultrasound has advanced slowly 
from low-resolution, bistable images to images with much greater detail. Currently, ultrasound image quality is sufficient to make it an important and often indispensable imaging modality in disease diagnosis and in obstetrics. ${ }^{192}$ Ultrasound imaging is now a mature technology, to the extent that it has a well-established place in clinical practice, as confirmed by the fact that it currently accounts for about one in four of all imaging procedures worldwide. However, this does not mean that the pace of development, either of the understanding of the physics of the interaction between ultrasound and tissue or of innovation in techniques, has slowed down. Indeed, the opposite is true. ${ }^{36}$

\section{Apparatus}

Methods for using ultrasound as a noninvasive thermometer fall into three categories: those based on echo-shifts due to changes in tissue thermal expansion and speed of sound (SOS), those that use the measurement of acoustic attenuation coefficient, and those exploit the change in backscattered energy (CBE) from tissue inhomogeneities. ${ }^{193}$

Ultrasound uses a nonionizing pressure wave generated by acoustic transducers usually placed on the skin of the patient to transmit sound into the body. This represents a convenient and inexpensive modality with relatively simple signal processing requirements. During its transit through the body, the pressure wave loses energy due to both scattering and absorption. Sound scattered out of the main beam may be used to form images; absorbed energy gives rise to tissue heating. Accordingly, ultrasound applications in medicine fall into two principal classes, diagnostic imaging and therapy, which differ in the power, intensity, and duration of the ultrasound. Medical ultrasound is perhaps best known for its diagnostic use in obstetrics. An ultrasound scan is now

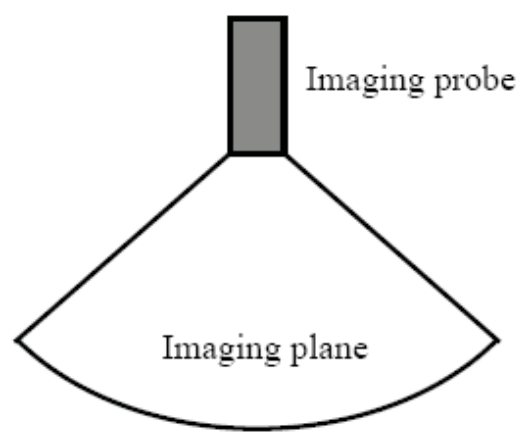

FIGURE 2. Ultrasound imaging plane. 
routinely offered to women early in pregnancy. Ultrasound imaging is used in many other fields of medicine, because it gives effective diagnostic information from a number of anatomical sites. Figure 2 shows an ultrasound-imaging plane.

The transducer is the most critical component in any ultrasonic imaging system. The trend for many years has been towards broader bandwidth transducers with more elements, since these will provide superior resolution at multiple depths by allowing the best possible compromise between penetration/resolution and attenuation. ${ }^{32}$ Nowadays, the transducers that are in clinical use almost exclusively employ a piezoelectric material, of which the artificial ferroelectric ceramic, lead zirconate titanate (PZT), is the most common. The ideal transducer for ultrasonic imaging would have a characteristic acoustic impedance perfectly matched to that of the human body, have high efficiency as a transmitter and high sensitivity as a receiver, a wide dynamic range, and a wide frequency response for pulse operation. ${ }^{36}$

Temperature dependence of ultrasonic tissue parameters has been reported extensively from in vitro analyses of ultrasonic tissue characteristics. ${ }^{194-197}$ These early investigators studied changes in tissue characteristics with temperature in order to evaluate thermal errors in tissue characterization.

\section{Advantages and Limitations}

Benefits claimed for ultrasound include the real-time visualization of applicator placement, portability of the technology, nearly universal availability, improved image quality, low cost, and ability to target and guide therapy with intracavitary endoluminal transducers (that is, for transrectal or transgastric energy application to the prostate and abdominal organs). Because of its ability to obtain blood flow and perfusion information via the Doppler effect, ultrasound is progressively achieving a broader role in radiology, cardiology, and image-guided surgery and therapy.

Ultrasound's limitations come mainly from its rapid attenuation by both bone and gas at the frequencies used, commonly 1-20 MHz. Other limitations of ultrasound include occasional poor lesion visualization as a result of overlying bone- or gas-containing structures. ${ }^{137}$ These attributes make it an attractive method to use for temperature estimation, if an ultrasonic parameter that is dependent on temperature can be found, measured, and calibrated. 


\section{Two- to Three-Dimensional Ultrasonography}

For more than a decade, one major goal in transducer development has been the construction of a fully electronic two-dimensional array that would allow for complete beam steering in three-dimensional space (axial, lateral, and azimuthal). ${ }^{198}$ Ultrasound systems that use twodimensional arrays keep the transducer stationary and use electronic scanning to sweep the ultrasound beam over the volume of interest to produce three-dimensional images in real time. Investigators have described a number of two-dimensional-array designs, but the one developed at Duke University for real-time three-dimensional echocardiography is the most advanced and has been used for clinical imaging. ${ }^{199}$ The transducer is composed of a two-dimensional phased array of elements that are used to transmit a broad beam of ultrasound that diverges away from the array and sweeps out pyramidal volumes. The returned echoes are detected by the two-dimensional array and then processed to display, in real time, multiple planes from the volume. These planes can be chosen interactively to allow the user to view the desired region under investigation.

In conventional two-dimensional ultrasonography, an experienced diagnostician manipulates the ultrasound transducer and mentally transforms the two-dimensional images into a three-dimensional comprehension of the lesion or anatomical volume necessary for the diagnosis or the interventional procedure. An alternative to the use of two-dimensional arrays is the use of a one-dimensional array, which is manipulated mechanically or manually to sweep out the desired volume of interest. As the transducer is moved over the anatomy, a series of two-dimensional images is recorded rapidly and then reconstructed into a three-dimensional image. If mechanical means are used to move the conventional transducer in a precise predefined manner, the relative position and angulations of each two-dimensional image can be accurately determined. The angular or spatial interval between the digitized two-dimensional images is usually made adjustable to minimize the scanning time while optimally sampling the volume.

Over the past two decades, many investigators have focused their efforts on the development of various types of three-dimensional imaging techniques by taking advantage of ultrasound positioning flexibility and data acquisition speed. ${ }^{200}$ These approaches have focused on reconstructing a three-dimensional image by integrating transducer position information with the two-dimensional ultrasound image. Because of the enormous demands on the computers needed to 
produce nearly real-time and low-cost systems, most attempts have not succeeded. It is only in the last few years that computer technology and visualization techniques have progressed sufficiently to make three-dimensional ultrasound imaging practical. It is now recognized that three-dimensional ultrasound imaging has an important role to play in ultrasound-guided therapies such as prostate cryosurgery and brachytherapy in addition to other clinical applications such as in diagnosing facial abnormalities and assessment of blood flow in various organs. Its role could be greatly expanded if a number of advances were achieved in coupling the three-dimensional image acquisition and display to therapy planning and monitoring. ${ }^{32,192}$

\section{VII.B. Magnetic Resonance Imaging (MRI)}

Magnetic resonance imaging is a relatively new technique that offers several advantages. It produces no ionizing radiation and provides superior tissue discrimination, lesion definition, an improved anatomic context for surrounding vessels and nerves, and excellent spatial resolution close to or in real time. The technique also permits characterization of functional and physiological parameters of tissues, including diffusion, perfusion, flow, and temperature. However, high costs are associated with MRI and it requires a special environment that can hinder patient accessibility. ${ }^{201}$

Magnetic resonance imaging is based on the principles of nuclear magnetic resonance (NMR), a spectroscopic technique used by scientists to obtain microscopic chemical and physical information about molecules. The technique was called MRI rather than NMR imaging (NMRI) because of the negative connotations associated with the word nuclear in the late 1970s. Magnetic resonance imaging started out as a tomographic imaging technique, that is, it produced an image of the NMR signal in a thin slice through the human body. It has advanced beyond a tomographic imaging technique to a volume-imaging technique. In 2003, there were approximately $10000 \mathrm{MRI}$ units worldwide, and approximately $75000000 \mathrm{MRI}$ scans performed each year. As the field of MRI continues to grow, so do the opportunities associated with it. ${ }^{202}$

\section{Operation}

Magnetic resonance thermometry has been in use since the 1990s for controlling interventional thermoablative procedures. ${ }^{203}$ Magnetic resonance imaging relies on the relaxation properties of excited 
hydrogen nuclei in tissue water. The object to be examined is positioned in a static external magnetic field, whereupon the spins of the protons align in one of two opposite directions: parallel or antiparallel. The protons process with a frequency determined by the strength of the magnetic field and the gyro-magnetic ratio. The object is then exposed to EM pulses with a frequency identical to the precession frequency in a plane perpendicular to the external magnetic field. For a 1-Tesla (T) scanner, a pulse frequency of $42.58 \mathrm{MHz}$ is used. The pulses cause some of the magnetically aligned hydrogen nuclei to assume a temporary non-aligned high-energy state. As the nuclei re-align, they emit energy that can be detected by a receiver coil. ${ }^{188}$ Figure 3 shows the main components of a MRI system.

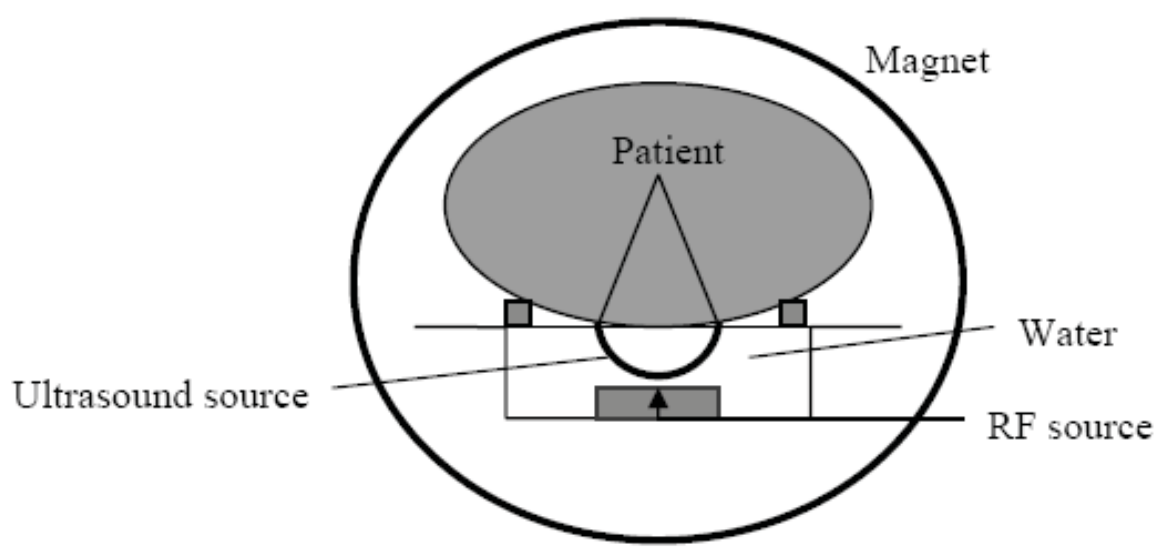

FIGURE 3. Magnetic resonance imaging.

The mechanical integration of any applicator for thermotherapy with magnetic resonance (MR)-tomographs is generally easy to realize. Conversely, interfaces with other methods for noninvasive thermometry (ultrasound or microwave imaging) are problematic. ${ }^{163}$ A particular advantage of MRI is that it not only allows temperature mapping, but it can be used for target definition and may provide an early evaluation of the therapeutic efficacy. ${ }^{24} \mathrm{~A}$ promising technique for noninvasive thermometry using NMR with CT has been proposed and studied by Kamimura and Amemiya. ${ }^{204}$

Implementing noninvasive monitoring for $\mathrm{RF} /$ microwave thermal therapy using the MR technique must solve the problem of EM compatibility: the interference between MR tomography (typically 
receiving and analyzing low-power signals in the microwatt range at $63.9 \mathrm{MHz}$ ) and thermal therapy $\mathrm{RF}$ applicator (transmitting power signals at therapeutic levels in the kilowatt range at hundreds of $\mathrm{Hz}$ ). Both of these systems must be operated simultaneously and without any interaction. In particular, the MR measurements must not be disturbed by any radiation from the thermal therapy system. ${ }^{205}$

Much of the current research in MRI guidance is directed toward thermal dosimetry. The high correlation of lesion formation with temperature provides a means to measure the treatment volume and quantify tissue damage. Several investigators have used MRI to measure temperature elevation during thermal therapy. ${ }^{205-213}$

\section{Advantages}

Magnetic resonance imaging is attractive in clinical medicine because it provides images with exquisite soft tissue contrast and it is completely noninvasive. ${ }^{214}$ The technique has demonstrated advantages over other imaging modalities in localizing tissue abnormalities and determining apparent tumor margins. It is, therefore, ideal for guiding various biopsies and tumor resections. Noninvasive MRI during thermal therapy treatments provides the capability to monitor changes in perfusion, temperature, necrosis, and chemistry. It is unique as an imaging modality in its ability to permit visualization of temperature changes dynamically, permitting thermal therapy to be monitored and controlled. Using MRI in conjunction with thermal therapy allows the surgeon to view the deposition of energy within the tissues while proceeding with therapy. ${ }^{215,216}$ However, high costs are associated with MRI. It requires a special environment that can hinder patient accessibility and minimal use of metal parts in the therapy assembly is necessary to prevent distortion of the MRI trends. ${ }^{201}$

Major current topics of study include the improvement of image quality in fast imaging, improvement of the accuracy of functional MRI (fMRI). Clinical applications of diffusion/perfusion imaging and the development of ultra-high magnetic field devices with magnetic field intensities above $10 \mathrm{~T}^{34}$

\section{VII.C. Microwave Radiometric Imaging}

Biomedical imaging techniques for the human body using microwave technology have been of interest for many years. Microwave images are maps of the electrical property distributions in the body. The electrical 
properties of various tissues may be related to their physiological state. ${ }^{217}$ Because EM radiation can be detected at a distance, microwave thermometry can be used to estimate a temperature at depths within the body even if the surface temperature is low.

Near-field microwave radiometry and radiometric imaging are noninvasive techniques that provide temperature information at a depth of up to several centimeters in subcutaneous tissues. They are based on the measurement of microwave thermal noise. ${ }^{23}$ The principle advantage of the microwave radiometer as a tool for biomedical imaging applications is the possibility to monitor a thermal noise produced by objects with temperature above absolute zero. Figure 4 shows the principle of imaging by microwave radiometer.

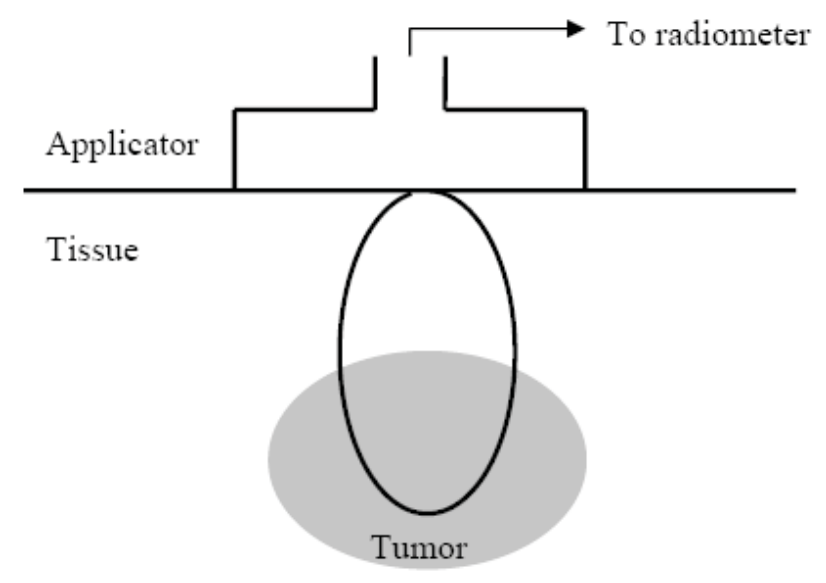

FIGURE 4. Principle of imaging by microwave radiometer.

Microwave radiometry permits monitoring of temperature increases under the surface of the body. Its main attraction is the innocuous nature of this type of energy at low levels, the relatively low cost of even complex microwave systems compared to the computer-assisted tomography (CAT) and MRI, and the distinctly different permittivity of tumor tissue compared to normal tissue..$^{23,40}$ Excellent reviews of the subject are those of Foster and Cheever ${ }^{21}$ and Rosen et al. ${ }^{23}$

Since the 1970s, several research groups have carried out clinical evaluations of microwave radiometry (passive, hybrid, and active approaches). ${ }^{218-237}$ The most important work was done by Barret et al. ${ }^{220}$ in the field of breast cancer screening. One thousand patients were 
examined at the Faulkner Hospital in Boston with microwave radiometry (operating at 1.3, 3.3, and $6 \mathrm{GHz}$ ) and infrared thermography. Breast cancer was confirmed with both methods in 39 patients. Microwave imaging has been explored as a new modality for breast cancer diagnosis since tissue physical properties are unique to the microwave spectrum, namely, the translucent nature of normal breast tissues and the significant contrast in the dielectric properties of normal tissue and malignant tumors. ${ }^{238,239}$ Although the specific contrasts vary with frequency and among the results from different groups, there is now a general belief that these contrasts are substantial, especially near 800 MHz. ${ }^{240-244}$

Other clinical evaluations were made with radiometers for measuring changes in lung water, ${ }^{222}$ cerebral temperatures, ${ }^{223}$ measurement of blood flow, ${ }^{225}$ and inflammatory arthritis. ${ }^{228}$

Current microwave imaging systems image biomedical objects of various sizes, sometimes even the full body. However, despite its unique capabilities, microwave radiometry has so far received only limited acceptance by the medical community and little commercial success. The chief reasons, we suspect, are the shallow depth of sensing and the difficulty of extracting imaging information from radiometry signals emitted by electrically heterogeneous media. A secondary factor has been the difficulty of validating many proposed clinical applications for the method-in particular, cancer detection. The implementation of a clinically viable microwave imaging system is a technically daunting task since high-resolution imaging requires a sophisticated scanned antenna array. On the signal processing side, it should be noted that the classical projection-type tomography algorithms are not applicable at microwave frequencies..$^{21,245}$ Microwave radiometry is a viable method of thermal sensing, but its successful applications are likely to be quite different than those that were originally conceived for the technique. ${ }^{21}$

\section{VII.D. Terahertz Technology}

Terahertz $(\mathrm{THz})$ radiation, which falls between microwaves and infrared light on the EM spectrum, occupies the region between approximately 0.3 and $20 \mathrm{THz}$. This region of the EM spectrum is sometimes called the "THz-gap". ${ }^{29}$ It is one of the least explored ranges of the EM spectrum. Radiation at these wavelengths is non-ionizing and subject to far less Rayleigh scatter than visible or infrared wavelengths, making it suitable for medical applications. Terahertz technology is gaining attention from researchers because it shows great promise for applications to 
the life sciences including medical imaging or even clinical treatment and chemical sensing. The energy levels of this band are very low (1-12 meV), therefore, damage to cells or tissue would be limited to generalized thermal effects, that is, strong resonant absorption seems unlikely. ${ }^{28,33,246}$

\section{Characteristics of $\mathrm{THz}$ Radiation}

Terahertz-ray imaging has several advantages when compared to other sensing and imaging techniques. While microwave and X-ray imaging modalities produce density pictures, THz-ray imaging also provides spectroscopic information within the $\mathrm{THz}$ range. The unique rotational, vibrational, and translational responses of materials (molecular, radicals, and ions) within the $\mathrm{THz}$ range provide information that is generally absent in optical, X-ray, and NMR images. ${ }^{31} \mathrm{THz}$-rays can also easily penetrate and image inside most dielectric materials, which may be opaque to visible light and in low contrast to X-rays, making THz-rays a useful and complementary imaging source in this context. The distinctive rotational and vibrational responses of biological tissues within the $\mathrm{THz}$ range provide information that cannot be offered by optical, X-ray, and MRI techniques.

A promising application of Terahertz technology in the medical area is early disease detection. The first use of this technology in this area was in the identification of dental caries ${ }^{247}$ and in the examination of skin to assess the magnitude and depth of burns. ${ }^{41}$ Recently, $\mathrm{THz}$ imaging was used to detect the extent of subdermal carcinomas. ${ }^{33}$

The excitement about $\mathrm{THz}$ imaging stems in part from its degree of penetration. Unlike $\mathrm{X}$-ray, $\mathrm{THz}$ radiation is nonionizing. Unlike ultrasound, $\mathrm{THz}$ waves can image without contact and they can go deeper than infrared radiation. Terhertz radiation puts much less energy into biological tissue than the above techniques. In addition, the use of X-rays raises safety concerns due to the use of ionizing radiation in regular screening. One advantage of $\mathrm{THz}$ imaging is the ability to perform spectroscopic measurements at each pixel in an image. This would allow, for example, the use of spectroscopy of tissue to identify regions of disease. $\mathrm{THz}$ medical imaging systems can be tuned to highlight specific types of tissue such as skin cancers. Because $\mathrm{THz}$ waves can penetrate plastic and cloth, they can be used to detect concealed objects. $\mathrm{THz}$ radiation is also capable of detecting chemicals like toxic gases and explosives. Among the challenges to making $\mathrm{THz}$ sensing and imaging applications more practical is finding ways to 
direct the waves to specific targets. Researchers are working to develop THz-wave guiding devices that are similar to the waveguides used to channel microwaves and light waves.

\section{THz-Ray System}

Until relatively recently, it was difficult to generate efficiently and detect $\mathrm{THz}$ radiation. At frequencies up to approximately $0.5 \mathrm{THz}, \mathrm{EM}$ radiation may be generated by electronic devices, including resonant tunneling diodes, Gunn devices, field effect or bipolar transistors. A second approach is to use lasers to produce $\mathrm{THz}$ radiation. ${ }^{29}$ Most $\mathrm{THz}$ sources are either low-brightness emitters with power output inversely related to the square of the frequency, or cumbersome, single-frequency molecular vapor lasers with limited operation. ${ }^{28-30}$

Detection usually relies on bolometers cooled by liquid helium, which require cryogenic operation and generally provide low sensitivity due to background radiation. These devices measure only the intensity of the radiation and do not provide any phase information. For these reasons, direct and coherent measurement of the $\mathrm{THz}$ electric field in the time domain is preferred. ${ }^{29}$

The challenges in $\mathrm{THz}$ imaging appear to lie primarily in the difficulties of fabricating solid-state $\mathrm{THz}$ sources. Researchers have focused attention on all optical techniques of producing $\mathrm{THz}$ radiation employing visible/near infrared lasers. Currently, most systems produce $\mathrm{THz}$ emissions by either frequency upconversion from the radiowave regime or by frequency downconversion from optical wavelengths. Common downconversion methods include photomixing, notably using semiconductor lasers typical for telecom applications operating at wavelengths of about $1.5 \mu \mathrm{m}$. An alternative is to irradiate a semiconductor microantenna with the infrared output, typically from a titanium-doped sapphire (Ti:Sapphire) laser with the output wavelength centered around $800 \mathrm{~nm} .{ }^{28-30}$

The first $\mathrm{THz}$ imaging systems were based on continuous-wave (CW) $\mathrm{THz}$ radiation. The setup is less expensive than conventional timedomain imaging systems that comprise femtosecond lasers. Continuouswave imaging affords a compact, simple, fast, and relatively low-cost system. The system uses a two-color external-cavity laser diode. Hence, it is much more compact than systems based on optically pumped solidstate lasers. The coherent detection scheme is phase sensitive and operates at room temperature. These low-cost, compact systems have image-capture rates comparable with those from state-of-the-art pulsed $\mathrm{THz}$ systems. 
Terahertz time-domain spectroscopy (THz-TDS) based on femtosecond lasers is one of the first and most interesting techniques to generate and detect $\mathrm{THz}$ radiation, which is based on frequency conversion using nonlinear optics (Figure 5). Using THz-TDS, the phase and amplitude of the $\mathrm{THz}$ pulse at each frequency can be determined. Like radar, THz-TDS also provides time information that allows us to develop various three-dimensional $\mathrm{THz}$ tomographic imaging modalities. The key components of a THz-TDS system are a femtosecond laser and a pair of specially designed transducers. By gating these transducers with ultrafast optical pulses, one can generate bursts of $\mathrm{THz}$ radiation and subsequently detect them with a high signal-to-noise ratio. These $\mathrm{THz}$ transients consist of only one or two cycles of EM field and they span a very broad bandwidth. Bandwidths extending from 100 $\mathrm{GHz}$ to $5 \mathrm{THz}$ can be obtained. By placing an object at the focus of the $\mathrm{THz}$ beam, it is possible to measure the waveform that has traversed through the object. By translating the object and measuring the transmitted $\mathrm{THz}$ waveform for each position of the object, one can build an image pixel by pixel. In order to form images in a reasonable time, the waveforms must be digitized and the desired information extracted on the fly. This can be accomplished using a commercial digital signal processor in a computer, which synchronizes the motion of the object through the focal spot with the waveform acquisition. ${ }^{28,248}$

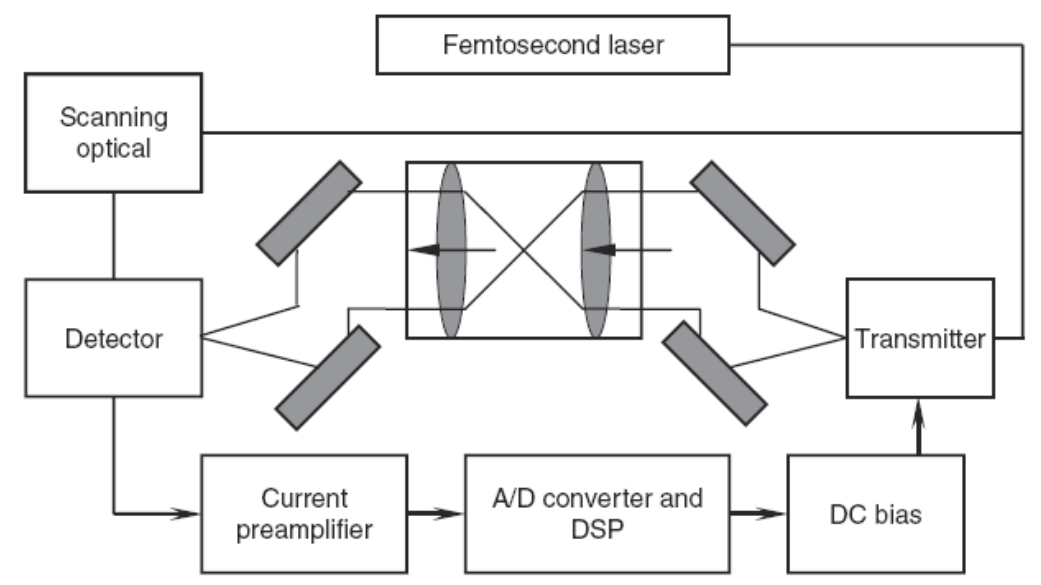

FIGURE 5. Schematic diagram of a Terahertz ( $\mathrm{THz})$ system. 


\section{Challenges}

The $\mathrm{THz}$ region of the EM spectrum was very difficult to explore until recent advances made the generation and detection of the radiation possible. ${ }^{29}$ Sensing and imaging with $\mathrm{THz}$ frequency for biomedical applications faces many challenges. These challenges include signal-tonoise ratio (SNR), high absorption rate of water, scattering, acquisition rate and resolution, and the need for a spectroscopic database for biological tissues. Solutions to the problem of SNR are sought in improving the THz-ray hardware. Terahertz sources have very low average output powers and $\mathrm{THz}$ sensors have relatively low sensitivity compared to sources and sensors operating in the optical range. Both of these aspects of THz-ray systems are foci of current research and continue to improve. ${ }^{31}$

Scattering is a common problem for many imaging modalities. THzrays exhibit significantly reduced scattering in human tissue compared to near-infrared optical frequencies due to the increased wavelength. Pearce and Mittleman ${ }^{249}$ investigated this issue using Teflon spheres and scattering related dispersion. This may allow the scattering process to be accurately modeled to aid the future development of diffusion imaging algorithms, such as those adopted for near-infrared imaging.

Perhaps one of the restrictive challenges facing $\mathrm{THz}$ imaging in biomedical engineering is the high absorption rate of water and other polar liquids. This strong absorption limits the sensing and imaging in water-rich samples and prohibits transmission-mode imaging through a thick tissue. For this reason, current biomedical $\mathrm{THz}$ research has primarily focused on skin conditions. ${ }^{31,250}$

Other disadvantages of $\mathrm{THz}$ system are the size and cost. Current THz-ray imaging systems require an area of a few square meters, most of which is dominated by the ultrafast laser. In addition, the high cost of ultrafast lasers (\$100 000-\$200 000) may impede THz imaging in a number of application settings. ${ }^{31}$

\section{VII.E. X-Ray Computed Tomography}

A computed tomography (CT) scan, also known as "CAT scanning" (Computed Axial Tomography), was developed in the early- to mid1970s and is now available throughout the world. The now-ubiquitous CT uses X-rays to make detailed pictures of structures inside the body. The scan is fast, patient friendly, and has the unique ability to image a combination of soft tissue, bone, and blood vessels. X-ray CT provides 
cross-sectional images of the chest, including the heart and great vessels. A CT scan can be used to study many parts of the body, such as the chest, belly, pelvis, or an arm or leg. It also can take pictures of organs, such as the liver, pancreas, intestines, kidneys, adrenal glands, lungs, and heart and can image blood vessels, bones, and the spinal cord.

By spinning the X-ray source and the sensor/detectors around the patient, data are collected from multiple angles. A computer then processes this information to create an image on a video screen. These images are called sections or cuts because they appear to resemble cross sections of the body. This technique eliminates the problem of conventional X-rays in which all the shadows overlap. Because X-rays form the image, this computerized technique has some limitations that are similar to those for plain film radiographs.

\section{Types of X-Ray CT Scanners}

The first successful CT images were produces at the Atkinson Morley Hospital in London in 1972 and were based on the achievement of the English engineer GN Hounsfield, who is now generally recognized as the inventor of computed tomography. ${ }^{186}$ In 1979 Hounsfield and Cormack, an engineer and a physicist, were awarded the Nobel Prize for Medicine in recognition of their outstanding achievements. ${ }^{35}$ Three main types of CT scanners are currently used in routine clinical practice. These include conventional, spiral, and multi-slice scanners.

\section{a. Conventional CT Scanners}

In the first generation (conventional) scanners, the tube produces a narrow beam of X-rays that passes through the patient and is picked up by a row of detectors on the other side. The tube and detectors are positioned on opposite sides of a ring that rotates around the patient. After each rotation, the scanner must stop and rotate in the opposite direction. Each rotation acquires an axial image, typically with a slice thickness of $1 \mathrm{~cm}$, taking approximately $1 \mathrm{~s}$ per rotation. The table moves the patient a set distance through the scanner between each slice. Conventional scanners have some limitations, for example, the first clinical scanners were slow and required $300 \mathrm{~s}$ for the acquisition of a single image. Such scanners are prone to artefact caused by movement or breathing. They reformat poorly in different planes do not permit studies of dynamic contrast, and small lesions between slices may be missed..$^{35,251}$ 


\section{b. Spiral (Helical) CT Scanners}

The basis for modern CT scanner and its success is an increase in speed of imaging compared to conventional scanners. This advance applies not only to the acquisition of single images, but also to the acquisition of image data of complete volumes of tissue. ${ }^{35}$ The incorporation of slip-ring technology into the design of scanners in the late 1980s removed the need for a rigid mechanical linkage between the power cables and the X-ray tube. This "simple" development, by enabling the tube to rotate in one direction indefinitely, has re-established CT at the forefront of imaging. While the tube is rotating, the table supporting the patient also moves continuously so that a volume of tissue rather than individual slices is scanned. The data are then reformatted automatically to display the images as axial slices. High quality reconstructed (reformatted) images in coronal, sagittal, and oblique planes can be readily acquired on a workstation. Spiral scanning has several advantages. Closely spaced scans are readily obtained, allowing good quality reconstructions in different planes. Lesions can be evaluated during different phases of contrast enhancement. Spiral computed tomography is a powerful diagnostic tool. A spiral scanner is not as fast as a multi-slice scanner but is considerably cheaper. ${ }^{251}$ The first clinical trials of spiral CT scanner were already completed in 1989; however, it took about three years for this scanner to receive wider acceptance. Spiral CT scanners provide scan times as short as $2 \mathrm{~s}^{35}$

\section{c. Multi-slice CT Scanners}

Since 1992, considerable technical development has been observed, providing significant increases in X-ray power and computing capacity. This development enhanced not only technical parameters and increased scan speed but also raised image quality by improving three-dimensional resolution and lesion detection. These potentials became clinical reality with the introduction of multi-slice CT system and rotation times of 0.5 $\mathrm{s}$ in the year $1998 .^{35} \mathrm{~A}$ multi-slice (multi-detector) CT scanner can be considered as a "turbocharged" spiral scanner. Conventional and spiral scanners use a single row of detectors to pick up the X-ray beam after it has passed through the patient. Multi-slice scanners currently have up to eight active rows of detectors and scanners under development will use direct digital detectors on flat panels. The increased number of detectors and tube rotation times that take a fraction of a second combine to give faster coverage of a given volume of tissue. ${ }^{251}$ The first years of the new millennium showed direct continuation of the development trends of the pervious decade. Image quality has reached a very high level that 
can be guaranteed even at the shorter examination times. Coronary angiography, for example, can be performed easily and noninvasively with 64-slice CT with scan times of less than $10 \mathrm{~s}$ providing impressive results. ${ }^{35}$

\section{VII.F. THz-Ray CT}

Terahertz CT is based on geometrical optics and inspired by X-ray CT. Like radar, based on the phase and amplitude of the $\mathrm{THz}$ pulse at each frequency, $\mathrm{THz}$ waves provide temporal and spectroscopic information that allows us to develop various three-dimensional $\mathrm{THz}$ tomographic imaging modalities. The hardware is a relatively simple extension of modern transmission mode THz-imaging systems. THz-ray CT extends $\mathrm{THz}$ imaging to enable the mapping of three-dimensional objects. It provides sectional images of objects in an analogous manner to conventional CT techniques such as X-ray CT. The interaction between a coherent $\mathrm{THz}$ pulse and an object provides rich information about the object under study; therefore, three-dimensional $\mathrm{THz}$ imaging is a very useful tool to inspect or characterize dielectric and semiconductor objects.

Terahertz-pulse imaging is used to obtain images of the target at multiple projection angles and the filtered backprojection algorithm enables the reconstruction of the object's frequency-dependent refractive index. Terahertz-ray CT directly measures the transmitted amplitude and phase of broadband pulses of $\mathrm{THz}$ radiation at multiple projection angles. The filtered back-projection algorithm then allows a wealth of information to be extracted from the target object including both its three-dimensional structure and its frequency-dependent far-infrared dielectric properties.

The applicability of the THz-ray CT technique is limited by two important restrictions: the $\mathrm{THz}$ power available and approximations made by the reconstruction algorithm. As THz-ray CT operates in transmission mode, it is only suitable for objects that do not attenuate or scatter the $\mathrm{THz}$ radiation too severely. This is a particular limitation for biomedical applications where the absorption of moist tissue is prohibitive. In addition, the current simple reconstruction algorithm does not describe the full interaction of $\mathrm{THz}$ radiation with complex structures and more sophisticated methods are required before strongly diffracting objects can be imaged accurately. ${ }^{252}$ 


\section{CHALLENGES AND FUTURE TRENDS}

\section{VIII.A. Dosimetry}

Theoretical dosimetry offers several clear advantages over the experimental approach. Accordingly, it has become an essential tool to complement experimental studies on biomedical engineering. Not only it is less expensive and faster than experimental work, but it also allocates the time evolution and spatial distribution of physical variables to be analyzed. The objective of EM and thermal dosimetry is to advance the calculation fields and heat to a level of sophistication where high-resolution SAR distribution and temperature profiles can be generated with computer graphics and displayed with anatomical features for any part of the human body.

Rapid and reliable EM and thermal distribution estimates are crucial for risk assessments and also for clinical planning of radiation treatment. Many clinical trials are being conducted to evaluate the effectiveness of thermal therapy. Despite positive outcomes, application of thermal therapy remains limited. This may partially relate to the lack of rigorous EM and thermal dosimetric data. Dosimetry should enable medical workers to write a verifiable prescription for thermal therapy. As in any form of therapy, a sound dosimetric basis leads to unambiguous treatment, data reporting, and quality assurance. ${ }^{5}$

Clinically, dosimetry enhances understanding of the biophysical phenomena involved in the EM heating of biological tissues. For this reason, procedures need to be developed that allow modeling of the realistic treatment conditions due to EM energy. Effects will also be directed at improving thermal models of organs under treatment so that expected temperature distributions due to EM energy can be predicted and displayed graphically.

Much of the future success in dosimetry will be based on:

1. accurate modeling of the electrical and thermal characteristics of biological tissues,

2. reliable techniques to quantify the thermal effect of the blood circulating in arteries and veins,

3. inclusion of nonlinear temperature-dependent tissue properties into the thermal model, and

4. development of fast computer simulation to better develop comparative thermal dosimetry that provides comparative evaluation of the potentials of different heating modes and configurations. 
Although not all aspects of dosimetry are covered, this review gives a rather comprehensive overview of the field. It is the strong consensus of the authors that a periodic review of this type is of benefit not only to the researchers but to all workers in this field.

\section{VIII.B. Thermometry and Imaging}

During the last four decades, there has been significant innovation and development in the field of thermometry and diagnostic imaging. Related techniques and modalities, which were only in the experimental research phase in the early 1970s and 1980s, have now become accepted clinical procedures worldwide. They include CT, MRI-based thermometry, ultrasound-based thermometry, microwave-based thermometry, and Terahertz (THz) imaging.

The choice of the modality should be based on robust evidence with regard to the accuracy and reliability of the temperature reading in the clinical setting for which it is intended. ${ }^{175}$ The consistent measurement of temperature distribution in living tissue is still the primary problem of thermometry although the measurement of other parameters, such as tissue properties, blood perfusion, or heat flux, is also of enormous importance. Important developments in this field are those related to noninvasive thermometry. This technique is used to visualize full threedimensional temperature distribution permitting easier and better controlled application of thermal therapy. ${ }^{253}$ Commonly, temperature measurement techniques require the insertion of several temperature monitoring probes into the tumor and normal surrounding tissues. Currently, invasive thermometry is absolutely necessary to determine the temperature distributions achieved. ${ }^{254}$ Invasive thermometry, besides providing extremely limited information about highly inhomogeneous thermal dose distributions, is a major clinical problem in the acceptance of thermal therapy. ${ }^{255}$ Efforts to establish noninvasive thermometry techniques with thermal therapy have been made in recent years. ${ }^{182,256}$ However, there are two issues that must be solved in order to implement noninvasive thermometry efficiently. First, the EM compatibility problem of interference between thermometry devices such as the MR tomograph and the thermal therapy applicator must be solved. Second, the acquisition process for a particular method of thermography must be carefully validated at first in a phantom under experimental conditions representative of a clinical setting. ${ }^{182,205}$

Magnetic resonance imaging could become the most widely used medical imaging modality if several developments, such as reducing the cost of an exam and designing smaller MRI systems, come about. 
Potential biomedical applications in $\mathrm{THz}$ imaging have emerged recently, spanning as diverse situations as contraband detection and tumor recognition. This tool provides spectroscopic information about the chemical composition as well as the shape and location of the targets these rays pass through or scatter from. Terahertz rays are nonionizing, as they have low photon energies (for example, typical X-ray photon energy is in the range of $\mathrm{keV}$, which is one million times more than that of a THz-ray photon). However, there remains a critical need for new initiatives and advanced technology developments in the $\mathrm{THz}$ band, especially the development of solid-state sources and detectors. The relatively unexplored $\mathrm{THz}$ band must remain a focus for future research.

Techniques for noninvasive thermometry and imaging were discussed in detail. Results presented in the literature have shown MRI, X-ray CT, and ultrasonic imaging to be adequate thermometry modalities. Other modalities including microwave and THz-based imaging have a promising future. In fact, the future of all thermometry and imaging techniques remains both exciting and challenging for biomedical engineering. Future research will indicate whether this promise evolves into reliable clinical techniques.

\section{REFERENCES}

1. Durney CH. Electromagnetic dosimetry for models of humans and animals: a review of theoretical and numerical techniques. Proc IEEE 1980;68:33-40.

2. Habash RWY. Electromagnetic fields and radiation: human bioeffects and safety. New York, NY: Marcel Dekker, 2001.

3. Vander Vorst A, Rosen A, Kotsuka Y. RF/microwave interaction with biological tissues. Hoboken, NJ: Wiley-IEEE Press, 2006.

4. Vecchia P. The approach of ICNIRP to protection of children. Bioelectromagnetics. 2005(Suppl 7):S157-S60.

5. Dewhirst MW, Prosnitz L, Thrall D, Prescott D, Clegg S, Charles C, MacFall J, Rosner G, Samulski T, Gillette E, LaRue S. Hyperthermic treatment of malignant diseases: current status and a view toward the future. Semin Oncol. 1997;24:616-25.

6. Myerson RJ, Strauble WL, Moros EG, Emami BN, Lee HK, Perez CA, Taylor ME. Simultaneous superficial hyperthermia and external radiotherapy: report of thermal dosimetry and tolerance to treatment. Int J Hyperthermia. 1999;15: 251-66.

7. Dewhirst MW, Sneed PK. Those in gene therapy should pay closer attention to lessons from thermal therapy. Int J Radiat Oncol Biol Phys. 2003;57:597-600.

8. Baiotto B, Marini P. Thermometry: clinical aspects and perspectives. In: Baronzio GF, Hager ED, Editors. Locoregional radiofrequency-perfusional and wholebody hyperthermia in cancer treatment: new clinical aspects. Eurokah.com and Springer Science Business Media, New York, 2005. 
9. Myerson RJ, Perez CA, Emami B, Straube W, Kuske RR, Leybovich L, Von Gerichten D. Tumor control in long-term survivors following superficial hyperthermia. Int J Radiat Oncol Biol Phys. 1990;18:1123-9.

10. Underwood HR, Burdette EC, Ocheltre KB, Magin RL. A multielement ultrasonic hyperthermia applicator with independent element control. Int J Hyperthermia. 1987;3:257-67.

11. Samulski TV, Grant WJ, Oleson JR, Leopold KA, Dewhirst MW, Vallario P, Blivin J. Clinical experience with a multi-element ultrasonic hyperthermia system: analysis of treatment temperatures. Int J Hyperthermia. 1990;6: 909-22.

12. Stauffer PR, Rossetto F, Leoncini M, Gentilli GB. Radiation patterns of dual concentric conductor microstrip antennas for superficial hyperthermia. IEEE Trans Biomed Eng. 1998;45:605-13.

13. Novak P, Moros EG, Straube WL, Myerson RJ. SURLAS: a new clinical grade ultrasound system for sequential or concomitant thermoradiotherapy of superficial tumors: applicator description. Med Phys. 2005;32:230-40.

14. Gazelle GS, Goldberg SN, Solbiati L, Livraghi T. Tumor ablation with radiofrequency energy. Radiology. 2000;217; 633-46.

15. Hudson RP, Marshak H, Soulen Jr RJ, Utton DB. Review paper: recent advances in thermometry below $300 \mathrm{mK}$. J Low Temp Phys. 1976;20:1-120.

16. Conway J, Anderson AP. Electromagnetic techniques in thermal therapy. Clin Phys Physiol Meas. 1986;7:287-381.

17. Fessenden P, Hand JW. Thermal therapy physics. In: Smith AR, Editor. Medical radiology: radiation therapy physics. Berlin, Heidelberg: Springer-Verlag, 1995.

18. Adair ER, Petersen RC. Biological effects of radiofrequency/microwave radiation. IEEE Trans Microw Theory Tech. 2002;50:953-62.

19. Cetas TC, Connor WG. Thermometry considerations in localized thermal therapy. Medical Physics. 1978;5:79-91.

20. Amemiya Y. Thermometry of thermal therapy. Gan No Rinsho. 1986; 32: 1653-60.

21. Foster KR, Cheever E. Microwave radiometry on biomedicine: a reappraisal. Bioelectromagnetics. 1992;13:567-79.

22. Hand J, Machin D, Vernon C, Whaley J. Analysis of thermal parameters obtained during Phase III trials of hyperthermia as an adjunct to radiotherapy in the treatment of breast carcinoma. Int J Hyperthermia. 1997;13:343-64.

23. Leroy $\mathrm{Y}$, Bocquet B, Mamouni A. Non-invasive microwave radiometry thermometry. Physiol Meas. 1998;19:127-48.

24. Denis De Senneville B, Quesson B, Moonen CTW. Magnetic resonance temperature imaging. Int J Hyperthermia. 2005; 21:515-31.

25. Jones E, Thrall D, Dewhirst MW, Vujaskovic Z. Prospective thermal dosimetry: the key to hyperthermia's future. Int J Hyperthermia. 2006;22:247-53.

26. Wust P, Cho CH, Hildebrandt B, Gellermann J. Thermal monitoring: invasive, minimal invasive and non-invasive approach. Int J Hyperthermia. 2006;22: 255-62.

27. Sherar MD, Trachtenberg J, Davidson SR, Gertner MR. Interstitial microwave thermal therapy and its application to the treatment of recurrent prostate cancer. Int J Hyperthermia. 2004;20:757-68.

28. Mittleman DM, Gupta M, Neelamani R, Baraniuk RG, Rudd JV, Koch M. Recent advances in terahertz technology. Appl Phys B. 1999;68:1085-94. 
29. Smye SW, Chamberlain JM, Fitzgerald AJ, Berry E. The interaction between terahertz radiation and biological tissue. Phys Med Biol. 2001;46:R101-R12.

30. Davies AG, Linfield EH, Johnston MB. The development of terahertz sources and their applications. Phys Med Biol. 2002;47:3679-89.

31. Zhang X-C. Terahertz wave imaging: horizons and hurdles. Phys Med Biol. 2002;47:3667-77.

32. Forsberg F. Ultrasonic biomedical technology; marketing versus clinical reality. Ultrasonics. 2004;42:17-27.

33. Siegel HS. Terahertz technology in biology and medicine. IEEE Trans Microw Theory Tech. 2004;52:2438-47.

34. Endo M. Recent progress in medical imaging technology. Sys Compu Jpn. 2005;36:1-17.

35. Kalender WA. X-ray computed tomography. Phy Med Biol. 2006;51:R29-R43.

36. Wells PNT. Ultrasound imaging. Phys Med Biol. 2006;51:R83-R98.

37. Larson LE, Jacobi JH. Medical applications of microwave imaging. New York: IEEE Press, 1986.

38. Miyakawa M, Bolomey J Ch. Non-invasive thermometry of the human body. Boca Raton, FL: CRC Press, 1995.

39. Dewhirst M. Thermal dosimetry: thermo-radiotherapy and thermochemotherapy. Berlin: Springer-Verlag, 1995.

40. Rosen A, Rosen HD. New frontiers in medical device technology. New York: Wiley, 1995.

41. Mittleman D. Terahertz imaging. In: Mittleman D, Editor. Sensing with terahertz radiation. Berlin, Germany: Springer-Verlag, 2003.

42. Ponne CT, Bartels PV. Interaction of electromagnetic energy with biological material-relation to food processing. Radiat Phys Chem. 1995;45:591-607.

43. Diller KR, Ryan TP. Heat transfer in living systems: current opportunities. Trans ASME. 1998;120:810-29.

44. Hubing TH. Survey of numerical electromagnetic modeling techniques. Electromagnetic Compatibility Laboratory. Report No TR91-1-001.3, University of Missouri-Rolla, Rolla, Missouri 1991.

45. Razansky D, Soldea DF, Einziger PD. Generalized transmission-line model for estimation of cellular handset power absorption in biological tissues. IEEE Trans Electromagn Compat. 2005;47:61-7.

46. Lin JC, Guy AW, Johnson CC. Power absorption in a spherical model of man exposed to 1-20 MHz electromagnetic field. IEEE Trans Microw Theory Tech. 1973;21:791-7.

47. Johnson CC, Durney CH, Massoudi H. Long wavelength electromagnetic power absorption in prolate spheroid models of man and animals. IEEE Trans Microw Theory Tech. 1975;23:739-47.

48. Barber PW. Electromagnetic absorption in prolate spheroidal models of man and animals at resonance. IEEE Trans Biomed Eng. 1977a;24:513-21.

49. Massoudi H, Durney CH, Johnson CC. Long wavelength analysis of plane wave irradiation of an ellipsoidal model of man. IEEE Trans Microw Theory Tech. 1977;25:41-6.

50. Barber PW. Resonance electromagnetic absorption by non-spherical dielectric objects. IEEE Trans Microw Theory Tech. 1977;25:373-81.

51. Caorsi S, Pastorino M, Raffetto M. Analytic SAR computation in a multilayer elliptic cylinder for bioelectromagnetic applications. Bioelectromagnetics. 1999;20:365-71. 
52. Caorsi S, Pastorino M, Raffetto M. Analytic SAR computation in a multilayer elliptic cylinder: the near-field line-current radiation case. Bioelectromagnetics. 2000;21:473-9.

53. Livesay DE, Chen KM. Electromagnetic fields induced inside arbitrary shaped biological bodies. IEEE Trans Microw Theory Tech. 1974;22: 1273-80.

54. Chen KM, Guru BS. Internal EM field and absorbed power density in human torso induced by 1-500 MHz EM waves. IEEE Trans Microw Theory Tech. 1977;25:746-56.

55. Barber PW, Gandhi OP, Hagmann MJ, Chatterjee I. Electromagnetic absorption in multilayered model of man. IEEE Trans on Biomed Eng. 1979;26:400-5.

56. King RWP. Electromagnetic field generated in model of human head by simplified telephone transceivers. Radio Sci. 1995;30:267-81.

57. Yee KS. Numerical solution of initial boundary value problems involving Maxwell's equations in isotropic media. IEEE Trans Antennas Propag. 1966;14:302-7.

58. Taflove A, Brodwin ME. Computation of the electromagnetic fields and induced temperatures within a model of the microwave irradiated human eye. IEEE Trans Microw Theory Tech. 1975a;23:888-96.

59. Taflove A, Brodwin ME. Numerical solution of steady state electromagnetic problems using the time dependent maxwell's equations. IEEE Trans Microw Theory Tech. 1975b;23:623-60.

60. Sullivan DM, Borup DT, Gandhi OP. Use of the finite difference time domain method in calculating absorption in human tissues. IEEE Trans Bioem Eng. 1987;34:148-57.

61. Spiegel RJ, Fatmi MBA, Stuchly SS, Stuchly MA. Comparison of finite-difference time-domain SAR calculations with measurements in a heterogeneous model of man. IEEE Trans Biomed Eng. 1989;36:849-55.

62. Taylor HC, Lau RWM. Evaluation of clinical thermal therapy treatment using time domain finite difference modeling technique. ACES Journal. 1992;7:85-96.

63. Gandhi OP, Gu Y-G, Chen J-Y, and Bassen H. I. Specific absorption rates and induced current distributions in an anatomically based human model for planewave exposures. Health Phys. 1992;63:281-90.

64. Kunz KS, Raymond JL. The finite difference time domain method for electromagnetics. Boca Raton, FL: CRC Press, 1993.

65. Watanabe S, Taki M, Kamimura Y. Frequency characteristics of energy deposition in human model exposed to near field of an electric or a magnetic dipole. IEICE Trans Commun. 1994;E77-B6:725-31.

66. Kuwano S, Kokubun K. Microwave power absorption in a cylindrical model of man in the presence of a flat reflector. IEICE Trans Commun. 1995;E78-B: 548-50.

67. Taflove A. Computational electrodynamics: the finite-difference time-domain method. Norwood, MA: Artech House, 1995.

68. Taflove A. Advances in computational electrodynamics: the finite-difference time-domain method. Norwood, MA: Artech House, 1998.

69. Lin JC, Hirai S, Chiang CL, Hsu WL, Su JL, Wang YJ. Computer simulation and experimental studies of SAR distributions of interstitial arrays of sleevedslot microwave antennas for thermal therapy treatment of brain tumors. IEEE Trans Microw Theory Tech. 2000;48:2191-7.

70. Hamada L, Saito K, Yoshimura H, Ito K. Dielectric-loaded coaxial-slot antenna 
for interstitial microwave thermal therapy: longitudinal control of heating patterns. Int J Hyperthermia. 2000;16:219-29.

71. Pisa S, Cavagnaro M, Piuzzi E, Bernardi P, Lin JC. Power density and temperature distributions produced by interstitial arrays of sleeved-slot antennas for hyperthermic cancer therapy. IEEE Trans Microw Theory Tech. 2003; 51:2370-88.

72. Chiu H-M, Mohan AS, Weily AR, Guy DJR, Ross DL. Analysis of a novel expanded tip wire (ETW) antenna for microwave ablation of cardiac arrhythmias. IEEE Trans Biomed Eng. 2003;50:890-9.

73. Kim J, Rahmat-Samii Y. Implanted antennas inside the human body: Simulations, designs, and characterizations. IEEE Trans Microw Theory Tech. 2004;52: 1934-43.

74. Jin JM. The finite element method in electromagnetics. Piscataway, NJ: John Wiley \& Sons, 1993.

75. Silvester PP, Pelosi G. Finite elements for wave electromagnetics. New York, NY: IEEE Press, 1994.

76. Shahidi A.V, Savard, P. A finite element model for radiofrequency ablation of the myocardium. IEEE Trans Biomed Eng. 1994;41:963-8.

77. Kaouk Z, Khebir A, Savard P. A finite element model of a microwave catheter for cardiac ablation. IEEE Trans Microw Theory Tech. 1996;44:8148-54.

78. Labonte S, Blais A, Legault SR, Ali HO, Roy L. Monopole antennas for microwave catheter ablation. IEEE Trans Microw Theory Tech. 1996;44:8132-40.

79. Haemmerich D, Staelin ST, Tungjitkusolmun S, Lee, FTJr, Mahvi DM, Webster JG. Hepatic bipolar radio-frequency ablation between separated multiprong electrodes. IEEE Trans Biomed Eng. 2001;48:1145-52.

80. Haemmerich D, Tungjitkusolmun S, Staelin ST, Lee FT, Mahvi DM, Webster JG. Finite element analysis of hepatic multiple probe radio-frequency ablation. IEEE Trans Biomed Eng. 2002;49:836-42.

81. Haemmerich D, Wright AS, Mahvi DM, Webster JG, Lee FT. Hepatic bipolar radiofrequency ablation creates lesions close to blood vessels: a finite element study. Med Biol Eng Comput. 2003;41:317-23.

82. Tungjitkusolmun S, Staelin S, Haemmerich D, Cao H, Tsai J-Z, Cao H., Webster JG, Lee FT, Mahvi DM, Vorperian VR. Three-dimensional finite element analyses for radio-frequency hepatic tumor ablation. IEEE Trans Biomed Eng. 2002;49:3-9.

83. Siauve N, Nicolas L, Vollaire C, Marchal C. 3D modelling of electromagnetic fields in local thermal therapy. Eur Phys J. 2003;21:243-50.

84. Kumaradas JC, Sherar MD. Optimization of a beam shaping bolus for superficial microwave thermal therapy waveguide applicators using a finite element method. Phys Med Biol. 2003;48:1-81.

85. Berjano EJ, Hornero F. Thermal-electrical modeling for epicardial atrial radiofrequency ablation. IEEE Trans Biomed Eng. 2004;51:1348-57.

86. Wu L, McGough RJ, Arabe OA, Samulski TV. An RF phased array applicator designed for thermal therapy breast cancer treatments. Phys Med Bio. 2006;51: $1-20$.

87. Ziskin MC. COMAR technical information statement: the IEEE exposure limits for radiofrequency and microwave energy. IEEE Eng Med Biol Mag. 2005;24: $114-7$.

88. Spiegel RJ. A review of numerical models for predicting the energy 
deposition and resultant thermal response of humans exposed to electromagnetic fields. IEEE Trans Microw Theory Tech. 1984;32: 730-46.

89. Durney $\mathrm{CH}$, Massoudi H, Iskander MF. Radiofrequency radiation dosimetry handbook. Brooks AFB, TX: USAF School of Aerospace Medicine, Aerospace Medical Division. USAFSAM-TR-85-73, 1986.

90. Habash RWH, Brodsky LM, Leiss W, Krewski DK, Repacholi M. Health risk of electromagnetic fields. Part II: Evaluation and assessment of radio frequency radiation. Crit Rev Biomed Eng. 2003;31:197-254.

91. Habash RWY. Electromagnetics-the uncertain health risks. IEEE Potentials. 2003;22:23-26.

92. Baiotto B, Marini P. Thermometry: clinical aspects and perspectives. In: Baronzio GF, Hager ED, Editors. Locoregional radiofrequency-perfusional and whole-body hyperthermia in cancer treatment: new clinical aspects. New York, NY: Eurokah.com and Springer Science Business Media, 2005.

93. Lagendijk JJW. Thermal therapy treatment planning. Phys Med Biol. 2000;45: R61-R76.

94. Field SB, Morris CC. The relationship between heating time and temperature: its relevance to clinical hyperthermia. Radiother Oncol. 1983;1:179-86.

95. Sapareto SA, Dewey WC. Thermal dose determination in cancer therapy. Int J Radiat Oncol Biol Phys. 1984;10:787-800.

96. Dewey WC. Arrhenius relationships from the molecule and cell to the clinic. Int J Hyperthermia. 1994;10:457-83.

97. Dewhirst MW, LaRue SM, Gerweck L. Tumor physiology and cell kinetics. Semin Vet Med Surg. 1995;10:148-57.

98. Weinbaum S, Jiji M. A new simplified bioheat equation for the effect of blood flow on local average tissue temperature. J Biomech Eng. 1985;107:131-9.

99. Chen Z, Roemer R. The effects of large blood vessels on temperature distributions during simulated hyperthermia. J Biomech Eng. 1992;84:473-81.

100. Gelvich E, Maxokhin V. Resonance effects in applicator water boluses and their influence on SAR distribution patterns. Int J Hyperthermia. 2000;16:83-128.

101. Acker J, Dewhirst M, Honore G, Samulski T, Tucker J, Oleson J. Blood perfusion measurements in human tumours: evaluation of laser Doppler methods. Int J Hyperthermia. 1990;6:287-304.

102. Dewey W, Hopwood L, Sapareto S, Gerweck L. Cellular responses to combinations of hyperthermia and radiation. Radiology. 1977;123:4631-74.

103. Oleson JR. Cumulative minutes with T90 greater than Tempindex is predictive of response to hyperthermia and radiation. Int J Radiat Oncol Biol Phys. 1993;25:841-7.

104. Kapp DS, Cox R. Thermal treatment parameters are most predictive of outcome in patients with single tumor nodules per treatment field in recurrent adenocarcinoma of the breast. Int J Radiat Oncol Biol Phys. 1995;33:887-99.

105. Thrall DE, LaRue SM, Yu D, Samulski T, Sanders L, Case B, Rosner G, Azuma C, Poulson J, Pruitt AF, Stanley W, Hauck ML, Williams L, Hess P, Dewhirst MW. Thermal dose is related to duration of local control in canine sarcomas treated with thermoradiotherapy. Clin Cancer Res. 2005;11:5206-14.

106. Kowalski ME, Jin J-M. A temperature-based feedback control system for electromagnetic phased-array thermal therapy: theory and simulation. Phys Med Biol. 2003;48:633Q51. 
107. Arkin H, Xu LX, Holmes KR. Recent developments in modeling heat transfer in blood perfused tissues. IEEE Trans Biomed Eng. 1994;41;97-107.

108. Joines WT, Spiegel RJ. Resonance absorption of microwaves by human skull, IEEE Trans Biomed Eng. 1974;21:46-8.

109. Lin JC. Microwave properties of fresh mammalian brain tissues at body temperature. IEEE Trans Biomed Eng. 1975;22:74-76.

110. Hagmann MJ, Gandhi OP. Numerical calculations of electromagnetic energy deposition in models of man with grounding and reflector effects. Radio Sci. 1979;14:23-9.

111. Karimullah K, Chen K-M, Nyquist DP. Electromagnetic coupling between a thin-wire antenna and a neighboring biological body: theory and experiment. IEEE Trans Microw Theory Tech. 1980;28:1281-25.

112. Xu Li, Hagness SC. A confocal microwave imaging algorithm for breast cancer detection. IEEE Microw Wirel Compon Lett. 2001;11:130-2.

113. Zhao H, Crozier S, Liu F. Finite difference time domain (FDTD) method for modeling the effect of switched gradients on the human body in MRI. Magn Reson Med. 2002;48:1037-42.

114. Liu F, Crozier S, Zhao H, Lawrence B. Finite-difference time-domain-based studies of MRI pulsed field gradient-induced eddy currents inside the human body. Concepts Magn Resonan (Part B: Magn Reson Eng). 2002;15:26-36.

115. Liu F, Beck BL, Xu B, Fitzsimmons JR, Blackband SJ, Crozier S. Numerical modeling of 11.1T MRI of a human head using a MoM/FDTD method. Concepts in Magn Reson (Part B: Magn Reson Eng). 2005;24B:28-38.

116. Wei Q, Liu F, Xia L, Crozier S. An object-oriented designed finite-difference timedomain simulator for electromagnetic analysis and design in MRI-applications to high field analyses. J Magn Reson. 2005;172:222-30.

117. Pennes HH. Analysis of tissue and arterial blood temperatures in the resting human arm. J Appl Physio. 1948;1:93-122.

118. Haines DE, Watson DD. Tissue heating during radiofrequency catheter ablation: a thermodynamic model and observations in isolated perfused and superfused canine right ventricular free wall. Pacing Clin Electrophysiol. 1989;12:962-76.

119. Diller KR. Modeling of bioheat transfer processes at high and low temperatures. Adv Heat Transfer. 1992;22:157-67.

120. Vrba J, Lapes M, Oppl L. Technical aspects of microwave thermotherapy. Bioelectrochem Bioenerg. 1999;48:305-9.

121. Shen W, Zhang J. Modeling and numerical simulation of bioheat transfer and biomechanics in soft tissue. Math Comput Model. 2005;41:1251-65.

122. Hardie D, Sangster AJ, Cronin NJ. Coupled field analysis of heat flow in the near field of a microwave applicator for tumor ablation. Electromagn Bio Med. 2006;25:29-43.

123. Liu J. Uncertainty analysis for temperature prediction of biological bodies subject to randomly special heating. J Biomed. 2001;34:1637-42.

124. Gowrishankar TR, Stewart DA, Martin GT, Weaver JC. Transport lattice models of heat transport in skin with spatially heterogeneous, temperature-dependent perfusion. Biomed Eng Online. 2004;3:42.

125. Erdmann B, Lang J, Seebass M. Optimization of temperature distributions for regional hyperthermia based on a nonlinear heat transfer model. Ann NY Acad Sci. 1998;858:36-46.

126. Tyréus PD, Diederich J. Theoretical model of internally cooled interstitial 
ultrasound applicators for thermal therapy. Phys Med Biol. 2002;47:1073-89.

127. Chan CL. Boundary element method analysis for the bioheat transfer equation. ASME J Biomech Eng. 1992;114:358-65.

128. Zhao J, Zhang J, Kang N, Yang F. A two level finite difference Scheme for one dimensional Pennes' bioheat equation. Appl Math Comput. 2002;171:320-31.

129. Jiang SC, Ma N, Li HJ, Zhang X. Effects of thermal properties and geometrical dimensions on skin burn injuries. Burns. 2002;28:713-7.

130. Mochnacki B, Majchrzak E. Sensitivity of the skin tissue on the activity of external heat sources. Comp Model Eng Sci. 2003;4:431-8.

131. Deng ZS, Liu J. Analytical study on bioheat transfer problems with spatial or transient heating on skin surface or inside biological bodies. ASME J Biomech Eng. 2002;124:638-49.

132. Zhu L, Xu LX, He Q, Weinbaum S. A new fundamental bioheat equation for muscle tissue-Part II: temperature of SAV vessels. ASME J Biomech Eng 2002; 124:121-32.

133. Brinck H, Werner J. Efficiency function: improvement of classical bioheat approach. J Appl Physiol. 1994;77:1617-22.

134. Wissler EH. Comments on Weinbaum-Jiji's discussion of their proposed bioheat equation. ASME J Biomech Eng. 1988;108:355-6.

135. Weinbaum S, Xu LX, Zhu L, Ekpene A. A new fundamental bioheat equation for muscle tissue: Part I-blood perfusion term. ASME J Biomech Eng. 1997;119: 278-88.

136. Keller KH, Seiler L. An analysis of peripheral heat transfer in man. J App Physiol. 1971;30:779-86.

137. Goldberg SN, Gazelle GS, Mueller PR. Thermal ablation therapy for focal malignancy: a unified approach to underlying principles, techniques, and diagnostic imaging guidance. AJR Am J Roentgenol. 2000;174:323-31.

138. Ahmed M, Goldberg SN. Thermal ablation therapy for hepatocellular carcinoma. J Vasc Interv Radiol. 2002;90:272-89.

139. Yu T-H, Zhou Y-X, Liu J. Development of a new mini-invasive tumour thermal therapy probe using high-temperature water vapour. J Medical Eng Tech. 2004;28:167-77.

140. Wissler EH. Pennes' 1948 paper revisited. J Appl Physiol. 1998;85:35-41.

141. Wissler EH. Steady-state temperature distribution in man. J Appl Physiol. 1961;16:734-40.

142. Wissler EH. Steady-state temperature distribution in man. Bull Math Biophys. 1964;26:47-66.

143. Wissler EH. A mathematical model of the human thermoregulatory behavior. Houston, TX: American Society Mechanical Engineering, 1981.

144. Stolwijik JAJ, Hardy JD. Temperature regulation in man-a theoretical study. Pflugers Arch. 1966;291:129-62.

145. Stolwijik JAJ, Cunningham DJ. Expansion of a mathematical model of thermoregulation to include high metabolic rates. NASA CR-92443 (NTIS N6916568) Washington, DC, 133 pp., 1968.

146. Stolwijik JAJ. Expansion of a mathematical model of thermoregulation to include high metabolic rates. NASA CR-102192 (NTIS NTD-195831). Washington, DC, 1969.

147. Stolwijik JAJ. Expansion of a mathematical model of physiological temperature regulation in man. NASA CR-1855 (NTIS N71-33401). Washington, DC, 1971. 
148. Song CWM, Shakil A, Griffin RJ, Okajima K. Improvement of tumor oxygenation status by mild temperature thermal therapy alone or in combination with carbogen. Semin Oncol. 1997;24:626-32.

149. Myrhage, R, Eriksson E.Vascular arrangements in hindlimb muscles of the cat. J Anat. 1980;131:1-17.

150. Wissler EH. Comments on the new bioheat equation proposed by Weinbaum and Jiji. ASME J Biomed Eng. 1987;109:226-32.

151. Baish JW. Formulation of the statistical-model of heat transfer in perfused tissue. ASME J Biomech Eng. 1994;116:521-7.

152. Sherar MD, Gladman AS, Davidson SRH, Trachtenberg J, Gertner MR. Helical antenna arrays for interstitial microwave thermal therapy for prostate cancer: tissue phantom testing and simulations for treatment. Phys Med Biol. 2001;46:1905-18.

153. Sayal DC, Maji NK. Thermoregulation through skin under variable atmospheric and physiological conditions. J Theor Biol. 2001;208:451-6.

154. Lang J, Erdmann B, Seebass M. Impact of nonlinear heat transfer on temperature control inregional hyperthermia. IEEE Trans Biomed Eng. 1999;46:829-38.

155. Liu J, Zhu L, Xu LX. Studies on the three-dimensional temperature transients in the canine prostate during transurethral microwave thermal therapy. ASME J Biomech Eng. 2000;122:372-9.

156. Zhu L, Dia C. Theoretical simulation of temperature distribution in the brain during mild hypothermia treatment for brain injury. Med Biol Eng Comput. 2001;39:681-7.

157. Wainwright PR. Thermal effects of radiation from cellular telephones. Phys Med Biol. 2002;45:2363-72.

158. Paulsen KD.Principles of power deposition models. In: Saegenschmiedt, Fessenden P, Vernon CC, Editors. Thermoradiotherapy and thermochemotherapy. Volume 1. New York, NY: Springer, 1995.

159. Clegg ST, Das SK, Fullar E, Anderson S, Blivin J, Oleson JR, Samulski TV.Thermal therapy treatment planning and temperature distribution reconstruction: a case study. Int J Thermal Therapy. 1996;12:65-76.

160. Lagendijk JJW. The influence of bloodflow in large vessels on the temperature distribution in thermal therapy. Phys Med Biol. 1982;27:17-23.

161. Kolios MC, Worthington AE, Sherar MD, Hunt JW. Experimental evaluation of two simple thermal models using transient temperature analysis. Phys Med Biol. 1998;43:3325-40.

162. Wust P, Gellermann J, Beier J, Wegner S, Tilly W, Troger J, Stalling D, Oswald H, Hege HC, Deuflhard P, Felix R. Evaluation of segmentation algorithms for generation of patient models in radiofrequency thermal therapy. Phys Med Biol. 1998;43:3295-307.

163. Van Rhoon GC, Wust P. Introduction: non-invasive thermometry for thermotherapy. Int J Hyperthermia. 2005;21:489-95.

164. Das SK, Clegg ST, Anscher MS, Samulski TV. Simulation of electromagnetically induced thermal therapy: a finite element gridding method. Int J Hyperthermia. 1995;11:797-808.

165. Das SK, Clegg ST, Samulski TV. Electromagnetic thermal therapy power optimization for multiple source applicators. Int J Hyperthermia. 1999;15: 291-308.

166. Paulsen KD, Geimer S, Tang J, Boyse WE. Optimization of pelvic heating 
rate distributions with electromagnetic phased arrays. Int J Hyperthermia. 1999;15:157-86.

167. Nadobny J, Sullivan D, Wust P, Seebass M, Deuflhard P, Felix R. A highresolution interpolation at arbitrary interfaces for the FDTD method. IEEE Trans Microw Theory Tech. 1998;46:1759-66.

168. Gellermann J, Wust P, Stalling D, Seebass M, Nadobny J, Beck R, Hege H, Deuflhard P, Felix R. Clinical evaluation and verification of the thermal therapy treatment planning system hyperplan. Int J Radiat Oncol Biol Phys. 2000;47:845-56.

169. Van de Kamer JB, De Leeuw AA, Hornsleth SN, Kroeze H, Kotte AN, Lagendijk JJ. Development of a regional thermal therapy treatment planning system. Int J Hyperthermia. 2001;17:207-20.

170. Van den Berg CAT, Bartels LW, De Leeuw AAC, Lagendijk JJW, Van de Kamer JB. Experimental validation of thermal therapy SAR treatment planning using MR B1+ imaging. Phys Med Biol. 2004;49:5029-42.

171. Kok HP, Van Haaren PM, Van de Kamer JB, Wiersma J, Van Dijk JD, Crezee J. High-resolution temperature-based optimization for hyperthermia treatment planning. Phys Med Biol. 2005;50:3127-41.

172. Kok HP, van Haaren PM, van de Kamer JB, Zum Vorde Sive Vording PJ, Wiersma J, Hulshof MC, Geijsen ED, van Lanschot JJ, Crezee J. Prospective treatment planning to improve locoregional hyperthermia for oesophageal cancer. Int $\mathrm{J}$ Hyperthermia. 2006;22:375-89.

173. Vitkin IA, Moriarty JA, Peters RD, Kolios MC, Gladman AS, Chen JC, Hinks RS, Hunt JW, Wilson BC, Easty AC, Bronskill MJ, Kucharczyk W, Sherar MD, Henkelman RM. Magnetic resonance imaging of temperature changes during interstitial microwave heating: a phantom study. Med Phys. 1997;24:269-77.

174. Ring EFJ. The historical development of thermometry and thermal imaging in medicine. J Med Eng Technol. 2006;30:192-8.

175. Crawford DC, Hicks B, Thompson MJ. Which thermometer? Factors influencing best choice for intermittent clinical temperature assessment. J Med Eng Tech. 2006;30:199-211.

176. Wunderlich C. On the temperature in diseases: A manual of medical thermometry. Translated from the 2nd German edition by W.B. Woodman. London: New Sydenham Society, 1871.

177. Oleson JR, Dewhirst MW, Harrelson JM, Leopold KA, Samulski TV, Tso CY. Tumor temperature distributions predict hyperthermia effect. Int J Radiat Oncol Biol Phys. 1989;16:559-70.

178. Issels RD, Prenninger SW, Nagele A, Boehm E, Sauer H, Jauch KW, Denecke H, Berger H, Peter K, Wilmanns W. Ifosfamide plus etoposide combined with regional hyperthermia in patients with locally advanced sarcomas: a phase II study. J Clin Oncol. 1990;8:1818-29.

179. Leopold K, Dewhirst M, Samulski T, Dodge RK, George SL, Blivin JL, Prosnitz LR, Oleson JR. Cumulative minutes with T90 greater than Tempindex is predictive of response to hyperthermia and radiation. Int $J$ Radiat Oncol Biol Phys. 1993;25:841-7.

180. Yeager CJ, Courts SS. A review of cryogenic thermometry and common temperature sensors. IEEE Sens J. 2001;1:325-60.

181. van Haaren PM, Kok HP, Zum Vorde Sive Vording PJ, van Dijk JD, Hulshof MC, Fockens P, van Lanschot JJ, Crezee J. Reliability of temperature and 
SAR measurements at oesophageal tumour locations. Int $J$ Hyperthermia. 2006;22:545-61.

182. Shantesh H, Naresh T, Mekala, Nagraj H. Thermometry studies of radiofrequency induced hyperthermia on hydrogel based neck phantoms. J Can Res Ther. 2005;1:162-7.

183. Fessenden P, Lee ER, Samulski TV. Direct temperature measurement. Cancer Res. 1984;44:4799S-4804S.

184. Hand JW. Heat delivery and thermometry in clinical thermal therapy. Recent Results Cancer Res. 1987;104:1-23.

185. Wust P, Gellermann J, Harder C, Tilly W, Rau B, Dinges S, Schlag P, Budach V, Felix R. Rationale for using invasive thermometry for regional thermal therapy of pelvic tumors. Int J Radiat Oncol Biol Phys. 1998b;41:1129-37.

186. Hounsfield GN. Computerized transverse axial scanning (tomography): I. Description of system. Brit J Radiol. 1973;46:1016-22.

187. Lawson RN. Implications of surface temperature in the diagnosis of breast cancer. Can Med Assoc J. 1956;75:309-10.

188. Frich L. Non-invasive thermometry for monitoring hepatic radiofrequency ablation. Minim Invasive Ther Allied Technol. 2006;15:18-25.

189. Meaney P, Paulsen K, Hartov A, Crane R. Microwave imaging for tissue assessment: initial evaluation in multitarget tissue-equivalent phantoms. IEEE Trans Biomed Eng. 1996;43:878-90.

190. Hynynen K, Chung A, Fjield T, Buchanan M, Daum D, Colucci V, Lopath P, Jolesz F. Feasibility of using ultrasound phased arrays for MRI monitored noninvasive surgery. IEEE Trans Ultrason Ferroelectr Freq Cont. 1996;43:1043-125.

191. Wild JJ, Reid JM. Application of echo-ranging techniques to the determination of the structure of biological tissues. Science. 1952;115:226-30.

192. Fenster A, Downey DB, Cardinal HN. Three-dimensional ultrasound imaging. Phys Med Biol. 2001;46:R67-R99.

193. Arthur RM, Straube WL, Trobaugh JW, Moros EG. Non-invasive estimation of thermal therapy temperatures with ultrasound. Int $\mathrm{J}$ Hyperthermia. 2005;21:589-600.

194. Jansson F, Sundmar E. Determination of the velocity of ultrasound in ocular tissues at different temperatures. Acta Ophthalmologica. 1961;39:899-410.

195. Gammell PMP, LeCroissette DH, Heyser RC. Temperature and frequency dependence of ultrasonic attenuation in selected tissues. Ultrasound Med Biol. 1979;5:269-77.

196. Shore D, Miles CA. Attenuation of ultrasound in homogenates of bovine skeletal muscle and other tissues. Ultrasonics 1988; 26: 218-23.

197. McCarthy RN, Jeffcort LB, McCartney RN. Ultrasound speed in equine cortical bone: effects of orientation, density, porosity and temperature. J Biomech. 1990;23:1139-43.

198. Light ED, Davidsen RE, Fiering JO, Hruschka TA, Smith SW. Progress in 2-D arrays for real time volumetric imaging. Ultrason Imag. 1998;20:35-250.

199. Smith SW, Trahey GE, von Ramm OT. Two-dimensional arrays for medical ultrasound. Ultrason Imag. 1992;14:213-33.

200. Fenster A, Downey DB. 3-D ultrasound imaging: a review. IEEE Eng Med Biol. 1996;15:41-51.

201. Vaezy A, Andrew M, Kaczkowski P. Image-guided acoustic therapy. Annu Rev Biomed Eng. 2001;3:375-90. 
202. Hornak JP. The basics of MRI. Online book (http://www.cis.rit.edu/htbooks/mri), 1996.

203. Quesson B, de Zwart JA, Moonen CTW. Magnetic resonance temperature imaging for guidance of thermotherapy. J Magn Reson Imag. 2000;12: $525-33$.

204. Kamimura Y, Amemiya Y. Automedica. Vol 8. New York: Gordon and Breach, pp. 295-313, 1987.

205. Gellermann J, Wlodarczyk W, Ganter H, Nadobny J, Fahling H, Seebass M, Felix R, Wist P. A practical approach to thermography in thermal therapy/ magnetic resonance hybrid system: validation in a heterogeneous phantom. Int J Radiation Biol Phys. 2005;61:267-77.

206. Cline HE, Hynynen K, Watkins RD, Adams WJ, Schenck JF, Ettinger RH, Freund WR, Vetro JP, Jolesz FA. Focused US system for MR imaging-guided tumor ablation. Radiology. 1995;194:731-7.

207. Fjield T, Hynynen K. The combined concentric-ring and sector-vortex phased array for MRI guided ultrasound surgery. IEEE Trans Ultrason Ferroelectr Freq Contr,. 1997;44:1157-67.

208. Carter DL, MacFall JR, Clegg ST, Wan X, Prescott DM, Charles HC, Samulski TV. Magnetic resonance thermometry during thermal therapy for human highgrade sarcoma. Int J Radiat Oncol Biol Phys. 1998;40:815-22.

209. McDannold NJ, Hynynen K, Wolf D, Wolf G, Jolesz FA. MRI evaluation of thermal ablation of tumors with focused ultrasound. J Magn Reson Imag. 1998;8:91-100.

210. Sokka SD, Hynynen K. The feasibility of MRI-guided whole prostate ablation with a linear aperiodic intracavitary ultrasound phased array. Phys Med Biol. 2000;45:3373-83.

211. Smith NB, Merilees NK, Hynynen K, Dahleh M. Control system for an MRI compatible intracavitary ultrasound array for thermal treatment of prostate disease. Int J Hyperthermia. 2001;17:271-82.

212. Marguet Ch, Melo de Lima D, Fakri-Bouchet L, Favre B, Cathignol D, Brigu A. NMR antenna for an interstitial ultrasound applicator. Eur Phys J. 2003;23, 213-6.

213. Arora D, Cooley D, Perry T, Guo J, Richardson A, Moellmer J, Hadley R, Parker D, Skliar M, Roemer RB. MR thermometry-based feedback control of efficacy and safety in minimum-time thermal therapies: phantm and in-vivo evaluations. Int J Hyperthermia. 2006;22:29-42.

214. Hu X, Norris DG. Advances in high-field magnetic resonance imaging. Anuu Rev Biomed Eng. 2004;6:157-84.

215. Bleier A, Jolesz FA, Cohen M, Weisskoff R. Real-time magnetic imaging of laser heat deposition in tissue. Magn Reson Med. 1991;21:132-7.

216. Higuchi N, Bleier AR, Jolesz FA, Colucci VM, Morris JH. MRI of the acute effects of interstitial neodymium:YAG laser on tissues. Investig Radiol. 1992;27: 814-21.

217. Fear EC, Meaney PM, Stuchly MA. Microwaves for breast cancer detection. IEEE Potentials. 2003;22:12-18.

218. Enander B, Larson G. Microwave radiometric measurements of the temperature inside a body. Electron Lett. 1974;10:315-7.

219. Edrich J, Hardee PC. Thermography at millimeter wavelength. Proc IEEE. 1974:62:1391-2. 
220. Barret AH, Myers PC, Sadowski NL. Detection of breast cancer by microwave radiometry. Radioscience. 1977;12:167-71.

221. Edrich J, Jobe WE, Hendee WR, Cacak HK, Gautherie M. Imaging thermograms at $\mathrm{cm}$ and mm wavelength. Ann NY Acad Sci. 1980;335:154-60.

222. Iskander MF, Durney $\mathrm{CH}$. Microwave methods of measuring changes in lung water. J Microwave Power. 1983;18:265-75.

223. Gustov AV, Troitskii VS, Gorbachev VP, Arzhanov NI, Tseitlina VN. Investigation of craniocerbral temperature by decimeter radiothermometry. Hum Physiol. 1985;8:69-72.

224. Leroy Y. Mamouni A, Can de Velde JC, Bocquet B, Dujardin B. Microwave radiometry for non-invasive thermometry. Automedia. 1987;8:88-202.

225. Gabrielian ES, Khachatrian LA, Nalbandian SG, Grigorian FA. Microwave method of determining cerebral blood flow (in Russian). Biull Eksp Biol Med. 1987;103:625-7.

226. Bocquet B, Van de Velde JC, Mamouni A, Leory Y, Giaux G, Delannoy J, Delvallee D. Microwave radiometric imaging at $3 \mathrm{GHz}$ for the exploration of breast tumors. IEEE Trans Microw Theory Tech. 1990;38:791-2.

227. Giaux G, Delanoy G, Delvalle D, Leroy Y, Mamouni A, Van de Velde JC, Bacquet B. Microwave radiometric imaging: characterization of breast tumours. J Photogr Sci. 1991;39:164-5.

228. MacDonald AG, Land DV, Sturrock RD. Microwave thermography as a noninvasive assessment of disease activity in inflammatory arthritis. Clin Rheumatol. 1994;13:589-92.

229. Bri S, Bellarbi L, Habibi M, ELKadiri M. Mamouni A. Experimental evaluation of new thermal inversion approach incorrelation microwave thermometry [tumour detection]. Electro Lett 2000; 36: 439-40.

230. Hand JW, Mizushina JMJ, Van de Kamer JB, Maruyama K, Sugiura T, Azzopardi DV, Edwards AD. Monitoring of deep brain temperature in infants using multi-frequency microwave radiometry and thermal modeling. Phys Med Biol. 2001;46:1885-903.

231. Mouty S, Bocquet B, Ringot R, Rocourt N, Devos P. Microwave radiometric imaging (MWI) for the characterisation of breast tumours. Eur Phys J. 2000;10:73-8.

232. Meaney PM, Fanning MW, Li D, Poplack P, Paulsen KD. A clinical prototype for active microwave imaging of the breast. IEEE Trans Microw Theory Tech. 2000;48:1841-53.

233. Jacobsen S, Stauffer P, Neuman D. Dual-mode antenna design for microwave heating and non-invasive thermometry of superficial tissue disease, IEEE Trans Biomed Eng. 2000;47:1500-09.

234. Jacobsen S, Stauffer PR. Multi-frequency radiometric determination of temperature profiles in a lossy homogeneous phantom using a dual-mode antenna with integral water bolus. IEEE Trans Microw Theory Tech. 2002;50:1737-46.

235. Davis SK, Tandradinata H, Hagness SC, Van Veen BD. Ultrawideband microwave breast cancer detection: a detection-theoretic approach using the generalized likelihood radio test. IEEE Trans Biomed Eng. 2005;52:1237-50.

236. Fear EC. Microwave imaging of the breast. Technol Cancer Res Treat. 2005;4: 69-82.

237. Hashemzadeh, Fhager A, Persson M. Experimental investigation of an optimization approach to microwave tomography. Electromagn Bio Med. 2006;25:1-12. 
238. Hagness SC, Taflove A, Bridges JE. Two-dimensional FDTD analysis of a pulsed microwave confocal system for breast cancer detection: fixed-focus and antennaarray sensors. IEEE Trans Biomed Eng. 1998;45:1470-9.

239. Hagness SC, Taflove A, Bridges JE. Three-dimensional FDTD analysis of a pulsed microwave confocal system for breast cancer detection: Design of an antenna-array element. IEEE Trans Antenn Propag. 1999;47:783-91.

240. Joines WT, Zhang Y, Li C, Jirtle RL. The measured electrical properties of normal and malignant human tissues from 50 to 900 MHz. Med Phys J. 1994;21: 547-50.

241. Caorsi GL, Gragnani L, Pastorino M. An electromagnetic imaging approach using a multi-illumination technique. IEEE Trans Biomed Eng. 1994;41:406-9.

242. Meaney PM, Paulsen KD, Hartov A, Crane RK. An active microwave imaging system for reconstruction of 2-D electrical property distributions. IEEE Trans Biomed Eng. 1995;42:1017-25.

243. Fear EC, Hagness SC, Meaney PM, Okoniewski M, Stuchly MA. Enhancing breast tumor detection with near field imaging. IEEE Microwave Magazine. 2002;March:48-56.

244. Fear EC, Stuchly MA. Microwave detection of breast cancer. IEEE Trans Microw Theory Tech. 2000;48:1854-63.

245. Huo Y, Bansal R, Zhu Q. Modeling of noninvasive microwave characterization of breast tumors. IEEE Trans Biomed Eng. 2004;51:1089-94.

246. Fitzgerald AJ, Berry E, Zinoveev EE, Walker GC, Smith MA, Chamberlain JM. An introduction to medical imaging with coherent terahertz frequency radiation. Phys Med Biol. 2002;47:67-84.

247. Crawley DA, Longbottom C, Cole BE, Ciesla CM, Arnone D, Wallace VP, Pepper M. Terahertz pulse imaging: a pilot study of potential application in dentistry. Caries Res. 2003;37:352-9.

248. Wang S, Zhang X-C. Pulsed terahertz tomography. J Phys D Appl Phys 2004;37: $1-36$.

249. Pearce J, Mittleman DM. Propagation of single-cycle terahertz pulses in random media. Opt Lett. 2001;6:2002-4.

250. Loffler T, Bauer T, Siebert KJ, Roskos HG, Fitzgerald A, Czasch S. Terahertz dark-field imaging of biomedical tissue. Opt Exp. 2001;9: 616-21.

251. Garvey CJ, Hanlon R. Computed tomography in clinical practice. BMJ. 2002;324:1077-80.

252. Ferguson B, Wang S, Gray D, Abbot D, Zhang X-C. T-ray computed tomography. Optics Lett. 2002;27:1312-4.

253. Wust P, Hildebrandt B, Sreenivasa G, Rau B, Gellermann J, Riess H, Felix R, Schlag PM. Hyperthermia in combined treatment of cancer. Lancet Oncol. 2002;3:487-97.

254. Lagendijk JJW, Hofman P, Schipper J. Perfusion analysis in advanced breast carcinoma during hyperthermia. Int J Hyperthermia. 1998;4:479-95.

255. Van der Zee, Peer-Valstar JN, Rietveld PJ, de Graaf-Strukowska L, Van Rhoon GC. Practical limitations of interstitial thermometry during deep hyperthermia. Int J Radiat Oncol Biol Phys. 1998;40:1205-12.

256. Chen JC, Moriarty JA, Derbyshire JA, Trachtenberg J, Bell SD, Doyle J, Arrelano R, Wright GA, Henkelman RM, Hinks RS, Lok S-Y, Toi A, Kucharczyk W. Prostate cancer: MR imaging and thermometry during microwave thermal ablation-initial experience. Radiology. 2000;214:290-7. 